\title{
Anaplastic large cell lymphoma: pathology, genetics, and clinical aspects
}

\author{
Naoko Tsuyama, ${ }^{1)}$ Kana Sakamoto, ${ }^{2)}$ Seiji Sakata, ${ }^{2)}$ Akito Dobashi, ${ }^{2)}$ Kengo Takeuchi ${ }^{1,2)}$
}

\begin{abstract}
Anaplastic large cell lymphoma (ALCL) was first described in 1985 as a large-cell neoplasm with anaplastic morphology immunostained by the Ki-1 antibody, which recognizes CD30. In 1994, the nucleophosmin (NPM)-anaplastic lymphoma kinase (ALK) fusion receptor tyrosine kinase was identified in a subset of patients, leading to subdivision of this disease into ALK-positive and -negative ALCL in the present World Health Organization classification. Due to variations in morphology and immunophenotype, which may sometimes be atypical for lymphoma, many differential diagnoses should be considered, including solid cancers, lymphomas, and reactive processes. CD30 and ALK are key molecules involved in the pathogenesis, diagnosis, and treatment of ALCL. In addition, signal transducer and activator of transcription 3 (STAT3)-mediated mechanisms are relevant in both types of ALCL, and fusion/mutated receptor tyrosine kinases other than ALK have been reported in ALK-negative ALCL. ALK-positive ALCL has a better prognosis than ALK-negative ALCL or other peripheral T-cell lymphomas. Patients with ALK-positive ALCL are usually treated with anthracycline-based regimens, such as combination cyclophosphamide, doxorubicin, vincristine, and prednisolone (CHOP) or CHOEP (CHOP plus etoposide), which provide a favorable prognosis, except in patients with multiple International Prognostic Index factors. For targeted therapies, an anti-CD30 monoclonal antibody linked to a synthetic antimitotic agent (brentuximab vedotin) and ALK inhibitors (crizotinib, alectinib, and ceritinib) are being used in clinical settings.
\end{abstract}

Keywords: pathology, immunohistochemistry, mutation, therapy, history

\section{HISTORY}

In 1985, Stein et al. first described anaplastic large cell lymphoma (ALCL) as a large-cell neoplasm with an anaplastic morphology labeled by the Ki-1 antibody, a monoclonal antibody raised against Hodgkin and Reed-Sternberg (H/RS) cells of classical Hodgkin lymphoma (CHL). ${ }^{1}$ The majority of these tumors harbor bizarre cells presenting abundant cytoplasm and prominent invasion of lymph node sinuses. They often resemble carcinoma and were sometimes diagnosed as anaplastic carcinoma, malignant histiocytosis, or non-lymphoid sarcoma. From immunohistological data, Stein considered that these neoplasms could be categorized as lymphoid neoplasms with T- or B-cell lineage (mostly T-cell phenotype) and therefore called them "anaplastic large-cell lymphomas" or other synonyms like "anaplastic large-cell Ki-1-positive lymphomas" in the original report. Subsequently, in 1988, the disease was defined in the updated Kiel classification as "large cell anaplastic (LCA) lymphoma, $\mathrm{Ki}-1$ positive", a type of high-grade lymphoma in the B- or T-cell category. ${ }^{2}$ The terminology "anaplastic large cell (ALC) lymphoma" was, however, preferred because the abbreviation LCA could be mistaken for leucocyte common antigen, which is also abbreviated as LCA. ${ }^{3}$ In 1994, the Revised European-American Lymphoma (REAL) classification regarded ALCL of a T/null-cell phenotype as a distinct entity, whereas ALCL of B-cell type was included in diffuse large B-cell lymphoma or primary mediastinal large B-cell lymphoma. ${ }^{4}$ The third edition of the World Health Organization (WHO) classification adopted the idea that ALK-positive and -negative ALCLs were the same disease entity. This concept shifted in the fourth edition, where only ALK-positive ALCL was listed as a distinct entity, whereas ALK-negative ALCL was considered a provisional entity. ${ }^{5}$ In the revised fourth edition of the WHO classification (2017), both lymphomas are listed as a distinct entity.

\section{EPIDEMIOLOGY AND ETIOLOGY}

ALCL, including ALK-positive and -negative ALCL, is a relatively rare subtype of non-Hodgkin lymphoma, accounting for $2 \%$ of total cases. ${ }^{6}$ Among the adult nodal T-cell lymphomas, ALCL is the third most common subtype of lymphoma, following peripheral T-cell lymphoma, not

\footnotetext{
Received: May 14, 2017. Revised: November 19, 2017. Accepted: November 21, 2017.

${ }^{1)}$ Division of Pathology, Cancer Institute, Japanese Foundation for Cancer Research, Tokyo, Japan, ${ }^{2}$ Pathology Project for Molecular Targets, Cancer Institute, Japanese Foundation for Cancer Research, Tokyo, Japan

Corresponding author: Kengo Takeuchi, MD., Pathology Project for Molecular Targets, the Cancer Institute, Japanese Foundation for Cancer Research. 3-8-31 Ariake, Koto, Tokyo 135-8550, Japan. E-mail: kentakeuchi-tky@umin.net
} 
otherwise specified (PTCL-NOS), and angioimmunoblastic T-cell lymphoma. ${ }^{7}$ In children, ALK-positive ALCL is the most common subtype of T-cell lymphoma and represents $10-30 \%$ of all lymphomas.

Virtually all cases of ALK-positive ALCL are caused by genetic translocations involving $A L K$. Although no potential risk factors have been clearly demonstrated, a study reported five cases of systemic ALK-positive ALCL involving the skin as having a possible relationship with insect bites. ${ }^{8}$

\section{CLINICAL FEATURES}

ALK-positive ALCL is most frequently observed in the first three decades of life, unlike ALK-negative ALCL (peak incidence, aged 40-65 years) and PTCL-NOS (very rare in children). A male predominance is observed, and the maleto-female ratio is approximately 1.2 to $3.0 .^{5,9-17}$ The majority (50-70\%) of patients present with stage III-IV advanced disease with peripheral, including mediastinal, and/or abdominal lymphadenopathy. ${ }^{5,10-14}$ Patients often have B symptoms $(54-75 \%),{ }^{5,9,10,12,13,15}$ and extranodal involvement is frequently observed (approximately $60 \%$ of cases). ${ }^{5,10,12,18}$ The most commonly found extranodal sites are the skin $(8-21 \%)$, bone $(12-17 \%)$, soft tissue $(17-21 \%)$, lung $(6-13 \%)$, liver $(3-17 \%)$, and spleen $(8-21 \%)$, as well as bone marrow $(0-16 \%),{ }^{5,9,10,12-14,19}$ In a report analyzing bone marrow involvement in ALCL, the incidence was $17 \%$ with histology only, whereas $40 \%$ of cases were found to be positive when immunohistochemistry was combined..$^{20}$ Circulating tumor cells or involvement of the gastrointestinal tract or central nervous system (CNS) are rarely detected at diagnosis. ${ }^{5,9,10}$ CNS relapse occurs in a small subset of patients. ${ }^{21-24}$ Notably, patients with the small cell variant may exhibit a leukemic presentation..$^{5,25,26}$ In a report from the International Peripheral T cell Lymphoma (IPTL) project, a retrospective study in which the clinical features of 87 patients with ALK-positive ALCL were analyzed, the incidence of abnormal laboratory results were as follows: lactate dehydrogenase (LDH) elevation (37\%), anemia (27\%), and thrombocytopenia $(10 \%){ }^{9}$

\section{HISTOPATHOLOGY}

Initially, ALCL was found to have distinct histopathological features of anaplastic large-cell proliferation. Subsequently, several studies demonstrated that ALCL showed morphological heterogeneity, exhibiting a large and pleomorphic, small-cell, Hodgkin-like, or sarcomatoid appearance. Currently, ALCL is thought to have a broad range of cytological features. Five morphological patterns are described in the fourth edition of the WHO classification based on the variability of cell size and morphology as well as histological architecture.

All morphological patterns shared the presence of large tumor cells, so-called "hallmark" cells, which were first termed by Benharroch et al. to be distinctive in ALCL..$^{15}$ The cells are large with a bizarre, horseshoe- or kidney-shaped nucleus, and have abundant cytoplasm. The background of the tumor cells differs with each histological variant. Although the different histological patterns do not seem to affect the prognosis, it is critical to differentiate ALKpositive ALCL from other T-cell lymphomas because the latter have a poorer prognosis. ${ }^{7}$ In most cases, ALK-positive ALCL can be identified by strong expression of CD30 and ALK in virtually all neoplastic cells. Thus, typical ALKpositive ALCL cases do not seem to present a diagnostic challenge. However, it should be noted that neither CD30 nor ALK is absolutely specific for ALCL; accordingly, the diagnostic significance of the expression of these proteins must be carefully assessed in combination with other phenotypic, morphological, clinical, and even genetic information.

\section{Common pattern}

The common variant of ALCL (C-ALCL) is, as the name suggests, the most frequent morphological form of ALCL, accounting for $60 \%$ or more of cases. ${ }^{15}$ Cytologically, the neoplastic cells represent the hallmark cells; these cells are typically large and contain round, oval, lobulated, horseshoeshaped, and bizarre nuclei (Figure 1), corresponding to the morphology of the cells in cases initially reported by Stein et al. Additionally, multinucleated and wreath-like tumor cells may be observed, often resembling H/RS cells of CHL. The cytoplasm is abundant compared with that in other nonHodgkin lymphomas and appears pale, amphophilic, basophilic, or eosinophilic. The characteristic pattern of invasion is lymph node sinus involvement and perivascular distribution, which can be found in approximately $75 \%$ of cases. ${ }^{15}$ The clusters of large cells packing the sinuses may mimic metastatic carcinoma. Partial effacement and surrounding of the residual germinal center are also observed.

C-ALCL has been reported to have two cytological forms. ${ }^{15,27,28}$ One is a typical pleomorphic large cell type, including multinucleated and H/RS-like cells, with pale cytoplasm, and the other is a relatively smaller and monomorphic cell type with basophilic cytoplasm. With regard to differential diagnosis, the former, a very large-cell type, should be distinguished from non-lymphoid malignancies, including poorly differentiated carcinoma, while the latter should be differentiated from non-ALCL PTCLs with monomorphic features. These two forms may not be clearly separated and instead are often mixed, exhibiting features of other morphological variants such as small cell and lymphohistiocytic patterns (described below). Additionally, several patterns may be observed in the same patient at different stages of the disease, suggesting that these morphological variants represent the different morphological appearances of a single disease. ${ }^{15,29,30}$

\section{Small cell pattern}

In the small cell variant of ALCL (S-ALCL), large hallmark cells are in the minority and the predominant population is small- to medium-sized tumor cells. This variant was first recognized by Kinney et al. in 1993 as primary Ki-1positive T-cell lymphoma with histological features different 
from typical ALCL, but with a $\mathrm{t}(2 ; 5)(\mathrm{p} 23 ; \mathrm{q} 35)$ translocation. ${ }^{26}$ They reviewed more than 100 cases of Ki-1-positive lymphoma and identified nine cases of the small-cell predominant variant.
Histologically, large hallmark cells can usually be identified in and around small vessels. These cells are highlighted by immunostaining for CD30 and ALK. S-ALCL was previously in the category of peripheral T-cell lymphomas other

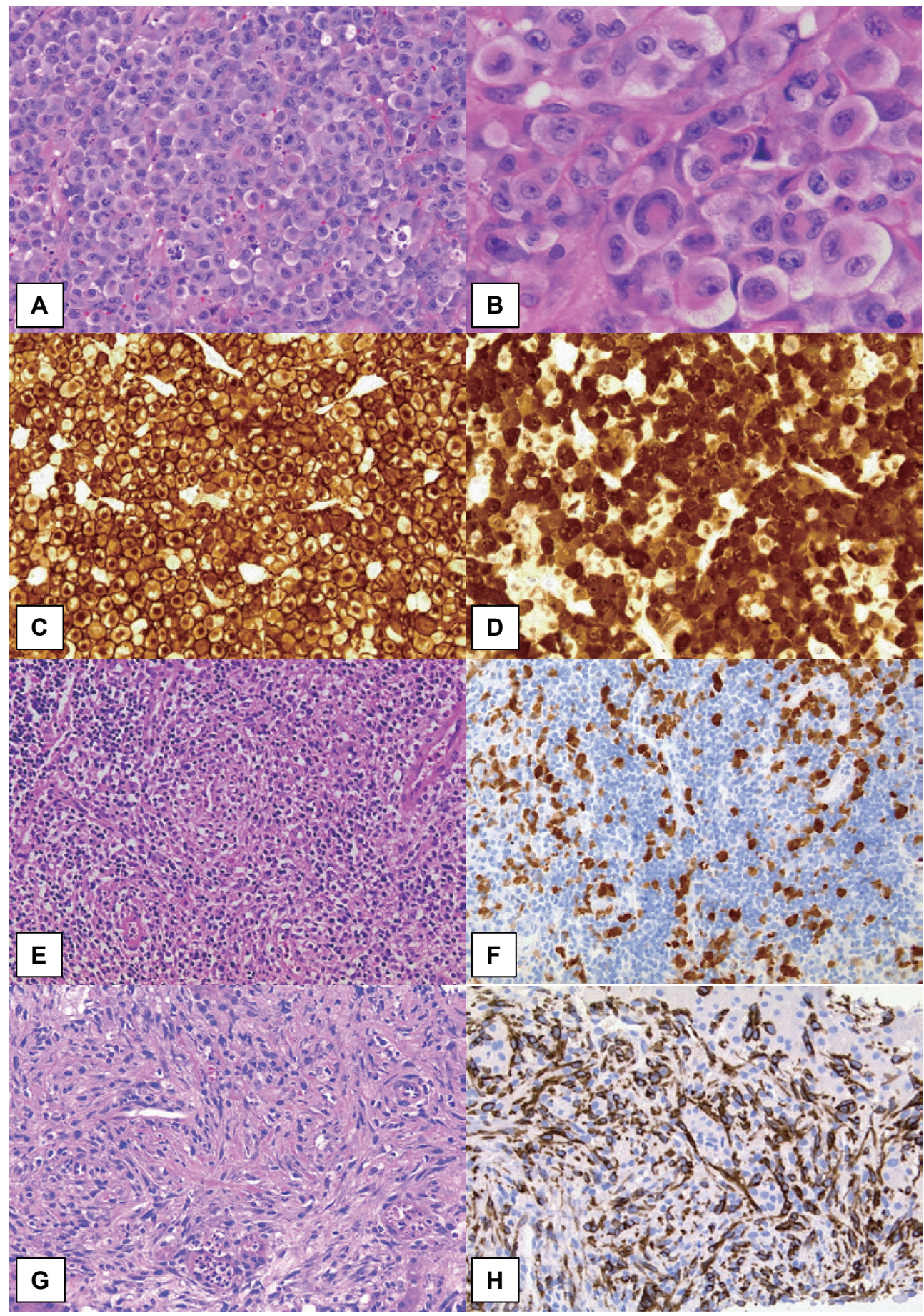

Fig. 1. Morphological patterns and immunostaining of ALK-positive ALCL.

The common pattern of ALK-positive ALCL comprises sheets of large, "hallmark" cell proliferation. Neoplastic cells exhibit variably shaped nuclei; invaginated, horseshoe- or kidney-shaped, donut-like, or Reed-Sternberg-like nuclei with abundant cytoplasm $(\boldsymbol{A}, \boldsymbol{B})$. Strong immunoreactivity for CD30 is generally observed both on the membrane and in the Golgi regions $(\boldsymbol{C})$. In cases of ALCL with the $t(2 ; 5)$ translocation, as shown in this figure, the ALK protein has both nucleolar and cytoplasmic staining pattern $(\boldsymbol{E}, \boldsymbol{F})$. The lymphohistiocytic pattern of ALCL shows conspicuous infiltration of small lymphocytes and histiocytes with pale cytoplasm. Morphologically, neoplastic cells are not clear but are highlighted by ALK immunostaining $(\boldsymbol{F})$. The sarcomatoid pattern of ALCL is characterized by atypical spindle-shaped cell proliferation with fascicular arrangement, simulating soft tissue sarcomas. Neoplastic cells are positive for CD30 $(\boldsymbol{H})$ and ALK expression $(\boldsymbol{G}, \boldsymbol{H})$. 
than ALCL; however, most cases of S-ALCL are associated with a component of the common pattern in the same lesion and are also mixed with a lymphohistiocytic variant of ALCL. Small neoplastic cells may or may not present strong CD30 expression, but exhibit positive ALK immunostaining with a nucleus-restricted pattern. ${ }^{31}$

\section{Lymphohistiocytic pattern}

The lymphohistiocytic variant of ALCL (LH-ALCL) comprises $10 \%$ of ALCL cases. In 1990, Pileri et al. first described this variant as "lymphohistiocytic T-cell lymphoma (anaplastic large cell lymphoma CD30+/Ki-1+ with a high content of reactive histiocytes)", and the authors suggested the possibility that this was a morphological variant of ALCL. ${ }^{32}$ Due to the unique components of the tumor, however, LH-ALCL was still defined as a separate lymphoma entity, called lymphohistiocytic lymphoma, in the updated Kiel classification. ${ }^{33}$ Subsequently, as the morphological spectrum of ALCL was expanded, LH-ALCL was described in the REAL classification as a subtype of ALCL. In 1997, the same group reported a case of LH-ALCL with ALK protein expression by immunohistochemistry, implying the presence of the $\mathrm{t}(2 ; 5)$ translocation. ${ }^{30}$ Then, in 1998, Ott et al. reported a similar case demonstrating the presence of the $\mathrm{t}(2 ; 5)(\mathrm{p} 23 ; \mathrm{q} 35)$ translocation and NPM-ALK fusion product, which provided evidence that LH-ALCL belonged to the same spectrum as C-ALCL. ${ }^{34}$

In LH-ALCL, tumor cells often have a minor component with an inflammatory background, with a large number of histiocytes and lymphocytes (Figure 1). Moreover, the tumor cells are generally smaller in size than those of C-ALCL, and larger cells are usually found around blood vessels. From these findings, a diagnosis of ALCL may be difficult to make if pathologists do not recognize these features of such a rare variant of ALCL. The histiocytes in this variant have pale or eosinophilic cytoplasm and round nuclei, and do not resemble epithelioid macrophages, as observed in well-formed granulomas of the lymphoepithelioid variant of PTCL (so-called Lennert lymphoma). Plasma cells and small lymphocytes are present; however, neutrophils and eosinophils are rarely found. The neoplastic cells may cluster around blood vessels, as in S-ALCL, and can be recognized by CD30 and ALK immunostaining.

\section{Hodgkin-like pattern}

The Hodgkin-like variant of ALCL (HL-ALCL) is defined not only by morphological features resembling those in nodular sclerosis CHL (NSCHL) but also by the expression of ALK protein as a result of the $A L K$ translocation. In the past, due to the striking morphological overlap between ALCL and CHL and the positivity of CD30 in neoplastic cells, cases of ALCL with features similar to those of CHL were originally reported as a variant of ALCL, referred to as "Hodgkin-related" or "Hodgkin-like" ALCL. ${ }^{35,36}$ In these reports, certain clinical similarities between HL-ALCL and NSCHL were also described, with frequent mediastinal involvement with bulky mass and relatively limited disease stage. Moreover, in 1995, Orscheschek et al. reported the presence of NPM-ALK chimeric mRNA using reverse transcriptase polymerase chain reaction (PCR)-based assays, demonstrating that the $\mathrm{t}(2 ; 5)$ translocation, reportedly exclusive to ALCL cases, also occurred in CHL cases and that CHL and ALCL had a common pathogenesis. ${ }^{37}$

However, after ALK immunostaining was developed, some cases thought to be HL-ALCL were shown to be negative for ALK and were subsequently reclassified as variants of CHL rich in tumor cells. Conversely, some histologically aggressive, prognostically poor subgroups of $\mathrm{CHL},{ }^{38}$ including NSCHL grade II or lymphocyte-depleted CHL, were found to be within the morphological spectrum of ALCL if ALK expression was identified. Now that ALCL is recognized as a T/null-cell neoplasm with $A L K$ translocation, whereas CHL is a B-cell neoplasm without $A L K$ translocation, the identification of ALK expression/translocation is the most definitive criterion distinguishing ALCL from CHL.

Histologically, HL-ALCL exhibits nodular lesions separated by thick fibrosclerotic bands, highly suggestive of NSCHL. There are a significant number of neoplastic cells, present either sparsely or cohesively, and some of them have the morphology of H/RS or lacunar cells of CHL. Thus, it is almost impossible, even for expert hematopathologists, to differentiate among these subtypes based on morphology only, and routine surveys with a panel of antibodies, including anti-ALK antibodies, are needed, particularly for cases suggestive of NSCHL. Although hallmark cells and sinus involvement are usually observed, they may occasionally be found in CHL. Reactive inflammatory cells, including macrophages, neutrophils, eosinophils, and small lymphocytes, also infiltrate in HL-ALCL, as observed in CHL; however, the dominant component of the lesion is proliferation of large tumor cells. ${ }^{35}$

\section{Composite pattern and other rare morphological patterns}

Approximately $30 \%$ of cases of ALK-positive ALCL have a mixture of more than one morphological variant; this is referred to as a composite pattern and has the common pattern with small or lymphohistiocytic patterns, as described earlier. Other rare morphological patterns, such as sarcomatoid, giant cell-rich, and signet-ring cell patterns, are also recognized in the fourth edition of the WHO classification.

The sarcomatoid variant of ALCL is extremely rare, and pathologists have difficulty in identifying this variant as a lymphoid tumor because proliferating cells exhibit a spindleshaped morphology, as typically observed in soft tissue sarcomas (Figure 1). ${ }^{39}$ This feature was first reported by Chan et al. in 1990 as a rare case of ALCL with a sarcomatoid growth pattern involving subcutaneous tissue and a lymph node. The histology mimicked malignant fibrous histiocytoma (fibroblastic/myofibroblastic tumor), and the case had a partial highly cellular area consisting of pleomorphic round, oval tumor cells or spindle-shaped cells with a swirling/storiform pattern, and a partly myxoid component with tumor cells was found to form cuffs around the blood vessels, similar to rosette formation. A few small lymphocytes and eosin- 
ophils were admixed.

\section{CD30 AND ALK}

The use of anti-CD30 and anti-ALK antibodies has facilitated the accurate identification of ALK-positive ALCL. Expression of CD30 and ALK is almost always strong and uniform in cases of C-ALCL; however, in some cases of other variants, including S-ALCL and LH-ALCL, strong staining may be observed only in a small number of admixed hallmark cells, which are often found around blood vessels. Furthermore, in S-ALCL, smaller tumor cells may be negative or only weakly positive for CD30. In contrast, many high-grade B- and T-cell lymphomas, particularly those with large pleomorphic cells or those associated with Epstein-Barr virus (EBV), may express CD30; however, these conditions can be distinguished from ALCL by analysis of a combination of other markers. Additionally, a rare form of large B-cell lymphoma, called ALK-positive large B-cell lymphoma (ALK-positive LBCL), which is positive for the ALK fusion, has been reported and described as a distinct entity in the current WHO classification. ${ }^{11,40-43}$

CD30 is a type 1 transmembrane protein (595 amino acids, $120 \mathrm{kDa}$ ) encoded by a gene located at chromosome $1 \mathrm{p} 36$ and is also known as tumor necrosis factor (TNF) receptor superfamily 8 (TNFRSF8). In the extracellular domain, CD30 has six cysteine-rich pseudo-repeat motives that show structural characteristics of TNFSF ${ }^{44}$ and a TNF receptor-associated factor (TRAF)-binding motif in the $\mathrm{C}$ terminus, mediating activation of nuclear factor- $\kappa \mathrm{B}(\mathrm{NF}-\kappa \mathrm{B}){ }^{45}$ Metalloproteinase-cleaved $85-\mathrm{kDa}$ soluble CD30 (sCD30) is found in the peripheral blood of patients with CD30-positive lymphomas or autoimmune diseases. ${ }^{46,47}$ The ligand of CD30 is a type II transmembrane protein, CD30L (CD153; 234 amino acids, $26 \mathrm{kDa}$ ) encoded by a gene located at chromosome $9 \mathrm{q} 33 .{ }^{44}$

CD30 is expressed by activated B and T lymphocytes. ${ }^{48}$ The expression of CD30 is also induced by mitogen stimulation such as phytohemagglutinin (PHA) and Epstein-Barr virus infection. ${ }^{1,49} \mathrm{CD} 30$ expression is usually observed in hematopoietic tumors, such as CHL and ALCL, and is uncommon in non-hematopoietic tumors, except embryonal carcinoma. CD30 expression is constitutively induced through the CD30/extracellular-regulated kinase (ERK)/mitogen-activated protein kinase (MAPK)/JunB signaling cascade, which regulates the CD30 promoter. ${ }^{50,51}$ The NPMALK fusion protein also induces JunB. ${ }^{52}$

CD30 activates the NF- $\mathrm{BB}$ pathway and MAPKs, including ERK, Jun N-terminal kinase (JNK), and p38. ${ }^{53-55}$ CD30 signaling also induces differential responses depending on the cell type. Thymocytes and mature T cells undergo apoptosis through this signal, ${ }^{56-59}$ which in turn induces the proliferation of activated $\mathrm{T}$ cells and other responses, including cell death, in several CD30-positive lymphoma-derived cell lines. ${ }^{60}$ In NPM-ALK-positive ALCL cells, the CD30 signal induces apoptosis, activation of the NF- $\kappa \mathrm{B}$ pathway, antiapoptotic effects through the p38 MAPK pathway, and growth inhibition via the cyclin-dependent kinase inhibitor p21 WAF/GIP. ${ }^{60-64}$ In contrast, in CHL cell lines, growth inhibition by CD30 signaling is not observed, ${ }^{61,62}$ and the NF- $\kappa \mathrm{B}$ and ERK1/2/MAPK pathways are constitutively activated, independent of ligands. ${ }^{50}$ The details of CD30 regulation and function remain unclear.

In humans, the $A L K$ gene is located at chromosome $2 \mathrm{p} 23$ and encodes a protein consisting of 1,620 amino acids. Unmodified ALK protein $(176 \mathrm{kDa})$ undergoes post-translational N-linked glycosylation and has a molecular weight of $220 \mathrm{kDa} .{ }^{65}$ ALK is a classical receptor tyrosine kinase belonging to the insulin receptor superfamily. There are two meprin A5 protein and protein phosphatase $\mu$ (MAM) domains, a low-density lipoprotein class A (LDL-A) domain, and a glycine-rich region in the extracellular region. The MAM domain is thought to play a role in cell-cell interactions. ${ }^{66}$ The function of the LDL-A domain is unclear; however, a previous study supported the idea that this domain functions as a ligand-binding site. ${ }^{67}$

In mice, ALK is strongly expressed in the nervous system during the embryonic stage and is then downregulated after birth; ${ }^{65}$ therefore, ALK is thought to function in neural development. Immunohistochemical studies have demonstrated that ALK is weakly expressed in adult nerve cells. ${ }^{68}$ Activation of ALK stimulates many signal pathways, including the RAS/RAF/MEK/ERK1/2, Janus kinase (JAK)/signal transducer and activator of transcription (STAT), phosphoinositol 3-kinase (PI3K)/AKT, and phospholipase C (PLC) $-\gamma$ pathways. ${ }^{69}$ The RAS/RAF/MEK/ERK $1 / 2$ and PLC- $\gamma$ pathways are related to cell proliferation, whereas the JAK/STAT and PI3K/AKT pathways regulate cell survival and phenotypic changes.

The most common form of $A L K$ aberration is fusion gene formation, reported in several types of human cancers (Table 1). Other aberrations include copy number gains and gain of function mutations in neuroblastomas. ${ }^{70}$ In most cases of fusion gene formation, exons 1-19 of $A L K$ (extracellular to transmembrane regions) are replaced with the 5' side of a partner gene by chromosomal rearrangement. The ALK kinase domain is retained in the fusion product. The partner genes usually have a domain responsible for dimerization or oligomerization. ${ }^{71}$

In 1994, the first ALK fusion protein, NPM-ALK, was reported in ALCL with $\mathrm{t}(2 ; 5)(\mathrm{p} 23 ; \mathrm{q} 35) .{ }^{72,73}$ Other ALK fusion partners reported in ALCL include TRK fused gene (TFG), tropomyosin 3 and 4 (TPM3 and TPM4), 5-aminoimidazole-4-carboxamide ribonucleotide formyltransferase/ IMP cyclohydrolase (ATIC), ring finger protein 213 (RNF213), clathrin heavy chain (CLTC), moesin (MSN), non-muscle myosin heavy chain (MYH9), and TRAF. ${ }^{74-82}$ NPM-ALK is the most common ALK fusion in ALK-positive ALCL (70-80\%), followed by TPM3-ALK (12-18\%; Figure 2, Table 2). Other fusions are rare. Among hematopoietic neoplasms other than ALCL, the following partners have been reported: CLTC, NPM1, SEC31 homolog A (SEC31A), sequestosome 1 (SQSTM1), RAN binding protein 2 (RANBP2), echinoderm microtubule associated protein like 


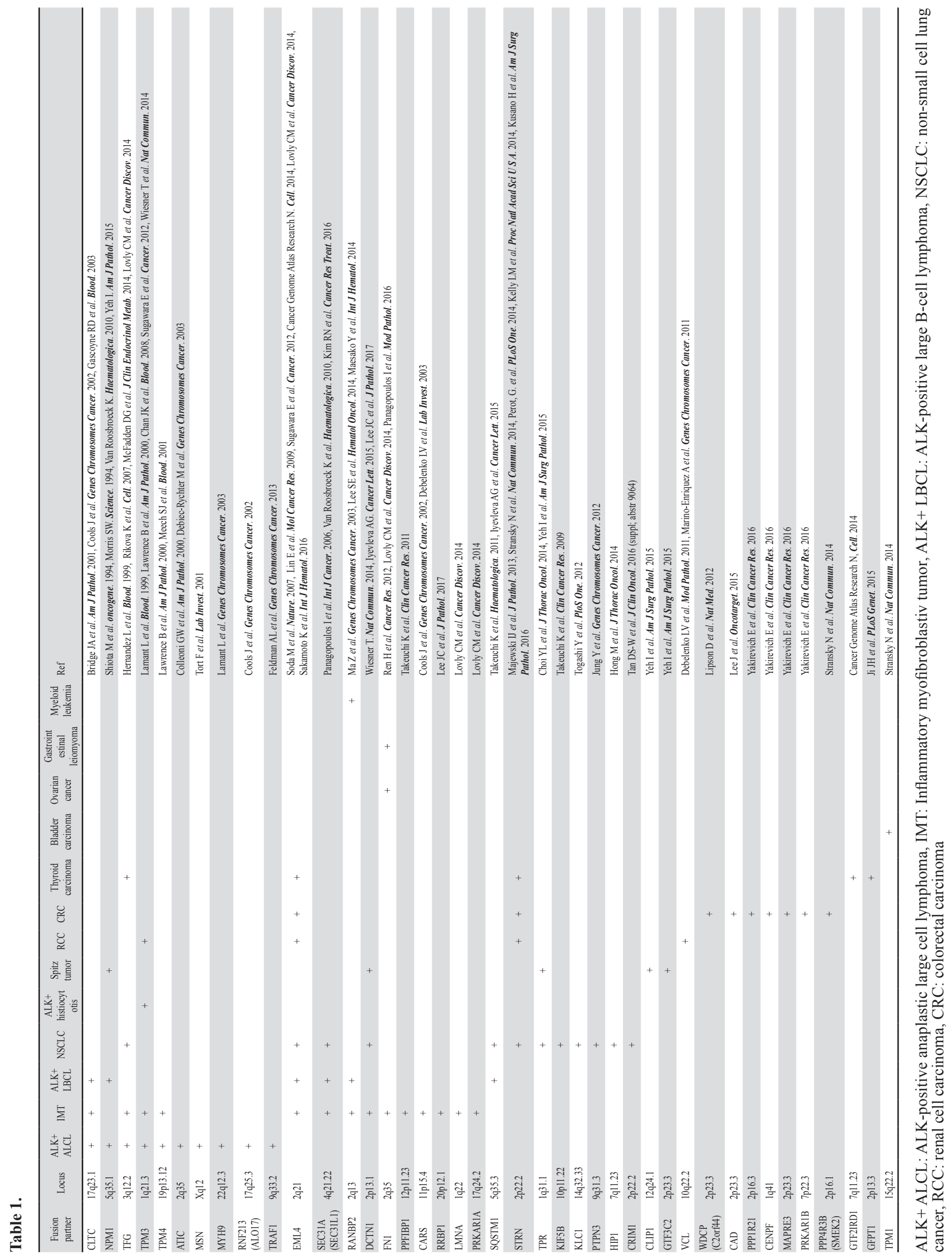




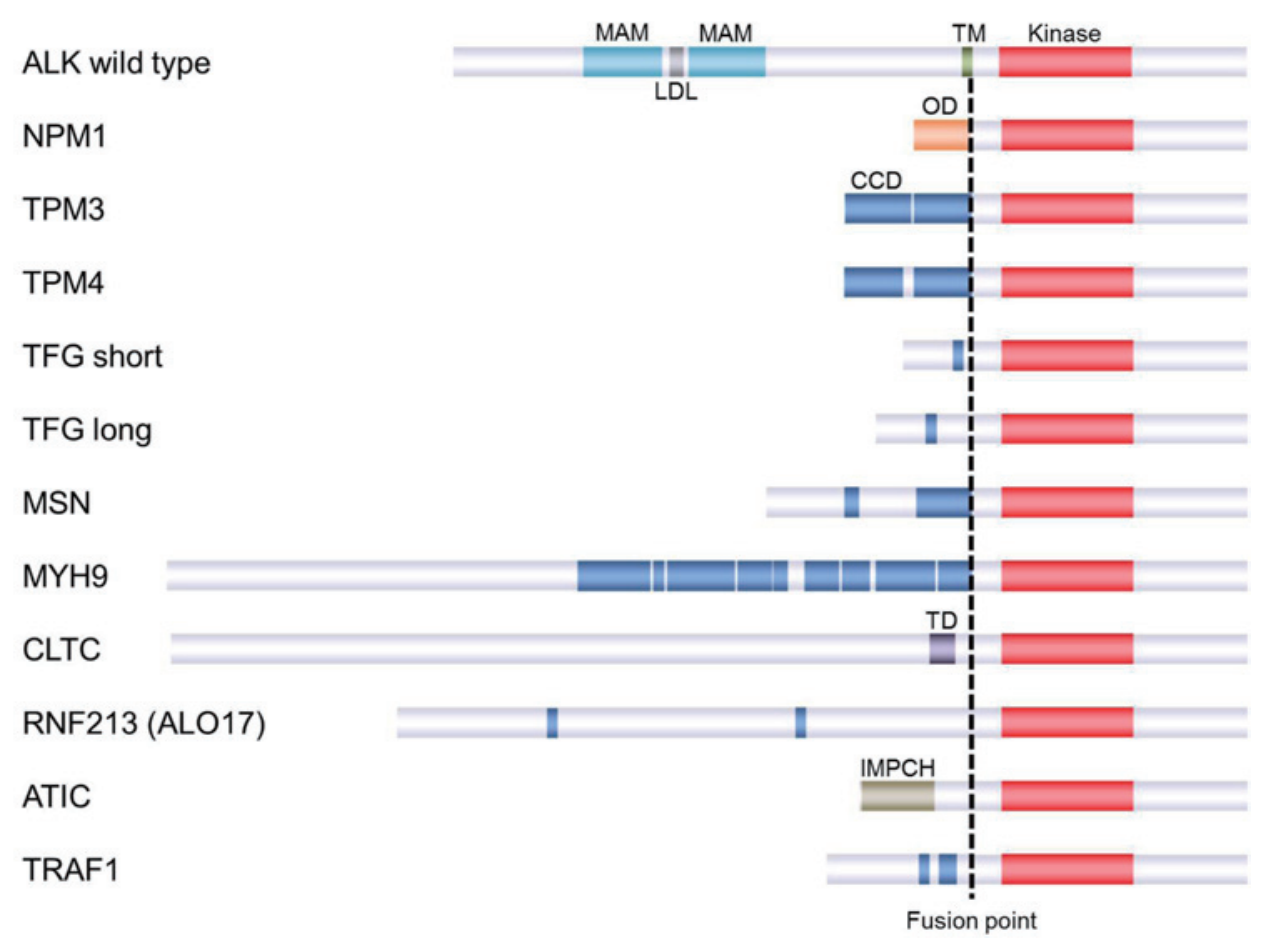

Fig. 2. ALK fusions reported in ALCL

Table 2. Genetic heterogeneity in anaplastic large cell lymphoma

\begin{tabular}{lll}
\hline ALK-positive ALCL & & \\
\hline NPM-ALK fusion gene & $5 \mathrm{q} 36.1$ & $\sim 80 \%$ \\
TPM3-ALK fusion gene & $1 \mathrm{p} 23$ & $\sim 15 \%$ \\
TFG-ALK fusion gene & $3 \mathrm{q} 12.2$ & rare \\
ATIC-ALK fusion gene & $2 \mathrm{q} 35$ & rare \\
CLTC-ALK fusion gene & $17 \mathrm{q} 23$ & rare \\
TPM4-ALK fusion gene & $19 \mathrm{p} 13$ & rare \\
MSN-ALK fusion gene & $\mathrm{Xp} 11.1$ & rare \\
ALO17-ALK fusion gene & $17 \mathrm{q} 25.3$ & rare \\
MYH9-ALK fusion gene & $22 \mathrm{q} 13.1$ & rare \\
TRAF1-ALK fusion gene & $9 \mathrm{q} 33.2$ & rare \\
\hline ALK-negative ALCL & & \\
\hline IRF4/DUSP22 locus rearrangements & & $30 \%$ \\
TP63locus rearrangements & & $8 \%$ \\
NFKB2-ROS1 fusion gene & & - \\
NCOR2-ROS1 fusion gene & & - \\
NFKB2-TYK2 fusion gene & & - \\
PABPC4-TYK2 fusion gene & & - \\
JAK1 and/or $S T A T 3$ mutations & & \\
truncated $E R B B 4$ & & \\
\hline
\end{tabular}

4 (EML4) in ALK-positive large B-cell lymphoma, ${ }^{43,83-86}$ TPM3 in ALK-positive histiocytosis, ${ }^{87}$ and RANBP2 in myeloid leukemia. ${ }^{88}$
In solid tumors, ALK fusions were first identified in IMT. In approximately $50 \%$ of IMT, ALK is fused to TPM3, TPM4, CLTC, ATIC, cysteiny1-tRNA synthetase (CARS), SEC31A, RANBP2, PPFIA binding protein 1 (PPFIBP1), fibronectin 1 (FN1), TFG, EML4, lamin A/C (LMNA), protein kinase cAMP-dependent type I regulatory subunit alpha (PRKAR1A), dynactin subunit 1 (DCTN1), or ribosome binding protein 1 (RRBP1). ${ }^{78,89-97}$ FN1-has also been reported in gastrointestinal leiomyoma. ${ }^{98}$

In 2007, EML4-ALK was reported in non-small cell lung cancer (NSCLC) ${ }^{99}$ this was the first description of an ALKpositive epithelial tumor. Although very rare, kinesin family member 5B (KIF5B), kinesin light chain 1 (KLC1), TFG, striatin (STRN), protein tyrosine phosphatase, non-receptor type 3 (PTPN3), Huntingtin interacting protein (HIP1), translocated promoter region protein (TPR), SEC31A, SQSTM1, DCTN1, and cysteine-rich transmembrane BMP regulator 1 (CRIM1) have also been reported to function as an ALK fusion partner in NSCLC. ${ }^{100-109}$ After the discovery of EML4-ALK in NSCLC, ALK fusions were explored and identified in different epithelial tumors, including renal cancer, ${ }^{110-113}$ colon cancer, ${ }^{114-118}$ breast cancer, ${ }^{114}$ ovarian cancer, ${ }^{119}$ thyroid cancer, ${ }^{116,120-124}$ and bladder cancer. ${ }^{116}$ The frequencies of these fusions are $1-2 \%$ in thyroid cancer ${ }^{120-123}$ and less than $1 \%$ in kidney and colon cancers. ${ }^{112,118}$

Recent studies have revealed that approximately $10 \%$ of Spitz tumors harbor ALK fusions. ${ }^{125}$ CAP-Gly domain-containing linker protein 1 (CLIP1) and general transcription factor IIIC subunit 2 (GTF3C2) were identified as new partners in Spitz tumors. ${ }^{126}$

ALK immunohistochemistry plays a central role in the diagnosis of ALK-positive tumors. As ALK expression is 
observed only in nerve cells, ALK immunohistochemistrypositive non-nerve cells are highly likely to have $A L K$ rearrangements.

The ALK immunostaining pattern reflects the subcellular localization of the ALK fusion protein. This localization is dependent on the ALK fusion partner. Therefore, it may be possible to identify the ALK fusion partner in each case based on the staining pattern. For example, NPM-ALKpositive cases exhibit a nuclear and cytoplasmic staining pattern. NPM has a nuclear localization signal in its C-terminus, and heterodimers of wild-type NPM and NPMALK translocate to the nucleus, whereas NPM-ALK homodimers remain in the cytoplasm. ${ }^{127}$ Currently, only NPM-ALK is known to exhibit nuclear positivity in ALK immunohistochemistry. Other characteristic ALK immunostaining patterns include a granular cytoplasmic pattern for CLTC-ALK, a cytomembrane and cytoplasmic pattern for TPM3-ALK, a cytomembrane pattern for MSN-ALK, and a nuclear membrane pattern for RANBP2-ALK. ${ }^{79,93,128}$

ALK immunohistochemistry is the gold standard for the diagnosis of tumors with ALK fusions. However, NSCLC with EML4-ALK is difficult to stain using standard ALK immunohistochemistry; indeed, in a study of 662 NSCLC cases in 2009, no tumors were immunostained for ALK. ${ }^{129}$ Highly sensitive ALK immunohistochemistry allows for the detection of the EML4-ALK fusion protein and is used as a diagnostic tool for ALK-positive NSCLC. ${ }^{101}$ Notably, highly sensitive ALK immunohistochemistry can also be used to detect low levels of wild-type ALK protein expressed in tumors with neuroendocrine differentiation, such as small cell carcinoma, although these tumors do not have ALK fusions. ${ }^{130,131}$ Alveolar rhabdomyosarcoma and neuroblastoma may also be positive in highly sensitive ALK immunohistochemistry. ${ }^{70,132}$

There are generally two types of assays used for fluorescence in situ hybridization analyses of fusion genes, i.e., fusion assays and split (break-apart) assays. In fusion assays, the two genes involved are stained in different colors with the fluorescence-labeled probes. When a mixed-colored signal is observed, the case is recognized as positive for the fusion gene. In split assays, 5'- and 3'-sides of the gene of interest are stained different colors. The gene is observed in the mixed color when it is not rearranged, and individual 5 '- and $3^{\prime}$-sides are observed when the sides are translocated by gene rearrangement. For genes that have many fusion partners, such as $A L K$, split assays are more appropriate for screening.

\section{IMMUNOPHENOTYPE OTHER THAN CD30 AND ALK}

Based on molecular evidence of the presence of clonal $\mathrm{T}$-cell receptor $(T C R)$ gene rearrangement, ALCL is now thought to originate from T cells. ${ }^{133-135}$ However, in ALCL, many cases represent an extensive loss of T-cell antigens, and in some cases, none of the lineage-specific markers can be detected; this is called the null-cell phenotype. ${ }^{15,133}$ The widely used pan-T-cell markers CD3, CD5, and CD7 are usually negative in the majority of cases, whereas CD2 and CD4 are most commonly preserved. CD8, a killer T-cell marker, is typically negative, whereas the cytotoxic molecules TIA-1 and granzyme B are positive. ${ }^{133,136}$ Antibodies against TCR proteins, such as TCR $\beta F 1$, are often negative in most cases, whereas rare cases have expression of TCR $\gamma \mathrm{M} 1$ together with TCR $\beta F 1$. Although exceptional cases of CHL may be positive for $\mathrm{CD} 3$ and $\mathrm{CD} 4$, staining for $\mathrm{CD} 3$ is usually not strong and exhibits cytoplasmic dot-like staining.

Some lymphoid or non-lymphoid markers are expressed in ALCL. Although not of diagnostic value, these markers are useful for discriminating between ALCL and other lesions. For example, epithelial membrane antigen (EMA), which is normally expressed on the surface of epithelial cells, is observed in the majority of ALCL cases but not in CHL or PTCL-NOS cases. ${ }^{137}$ Neoplastic/non-neoplastic large cells with EBV-related markers are identified in some cases of CHL, PTCL-NOS, and large B-cell lymphoma; however, ALCLs are consistently negative for EBV detected either by in situ hybridization for EBV-encoded RNA or by immunostaining of latent membrane protein (LMP1) antigen. ALCL is typically negative for CD15 antigen, which is expressed in approximately $75 \%$ of CHL, but may be present in occasional cases of ALCL. ${ }^{138}$ Myelomonocytic markers, such as CD13, CD33, and CD68 (KP-1), are occasionally expressed and should not be misinterpreted for myeloid or histiocytic neoplasms. ${ }^{139}$

No B-cell form of ALCL has been described in the current classification, and the expression of B-cell markers is a key finding in the differential diagnosis between ALCL and B-cell neoplasms, including CHL. However, rare cases of ALCL may aberrantly express the B-cell lineage transcription factor, PAX5, which is one of the most useful markers for making a diagnosis of CHL. Feldman et al. reported four cases of PAX5-positive ALCL, including one ALK-positive ALCL. ${ }^{140}$ The authors revealed extra copies of the PAX5 gene locus by fluorescence in situ hybridization analysis and identified the possible association of weak PAX5 immunostaining in rare ALCL cases.

\section{MOLECULAR ALTERATIONS OTHER THAN ALK}

In most ALCL cases (74-90\%), TCR genes are clonally rearranged. However, TCRs and some related molecules are usually not expressed in ALK-positive or -negative ALCL. ${ }^{133,141}$ Overexpression of NPM-ALK induces downregulation and/or epigenetic silencing of these molecules, including CD3 8 , zeta-chain-associated protein kinase 70 (ZAP70), linker for activation of T cells (LAT), and lymphocyte cytosolic protein 2 (LCP2) via STAT3, whereas kinasedead NPM-ALK K210R does not. ${ }^{142}$ Deregulated tyrosine kinases, such as NPM-ALK, control the expression of molecules involved in T-cell identity and signaling. ${ }^{142}$

In 2016, Hassler et al. reported that DNA methylation patterns for genes involved in T-cell differentiation and 
immune response, including TCRs and CTLA4, were similar between ALK-positive and -negative ALCL. ${ }^{143}$ The DNA methylation patterns of ALCLs were similar to those of thymic progenitor T cells; ALK-positive ALCL resembled early thymic progenitors (CD34+/CD1a-) and ALK-negative ALCL more closely resembled pre-TCR and double-positive (CD4+/CD8+) T cells..$^{143}$

Microarray-based gene expression profiling of 32 clinical samples and five ALCL cell lines was carried out. ${ }^{144}$ Unsupervised analysis classified that these samples could be grouped into two clusters corresponding to the morphologic subgroups (common type versus small cell and "mixed" variants). ${ }^{144}$ ALK-positive and -negative ALCLs were revealed to have different profiles; $B C L 6, P T P N 12, C E B P B$, and SERPINA1 genes were overexpressed in ALK-positive ALCL, whereas CCR7, CNTFR, IL22, and IL21 genes were overexpressed in ALK-negative ALCL. ${ }^{144}$ Both types of ALCL expressed high levels of interferon regulatory factor 4 (IRF4), which induces MYC expression. ${ }^{145}$

Comparative genomic hybridization analysis of 43 ALKpositive and 31 ALK-negative ALCLs revealed that ALKpositive (58\%) and -negative (65\%) ALCLs had chromosomal imbalances. ${ }^{146}$ ALK-positive ALCL demonstrated more frequent gains in $17 \mathrm{p}$ and $17 \mathrm{q} 24$-qter and losses of 4q13-q21 and 11q14, whereas ALK-negative ALCL showed gains in $1 \mathrm{q}$ and $6 \mathrm{p} 21 .{ }^{146}$

To the best of our knowledge, the results of next-generation sequencing analyses for ALK-positive ALCL are not yet available; however, those for ALK-negative ALCL are providing insights into the oncogenic mechanisms of this alteration (Table 2). JAK1 and/or STAT3 mutations were identified in $18 \%$ of ALK-negative ALCL by whole-exome sequencing. ${ }^{147}$ STAT3 mutants were found to exhibit constitutive phosphorylation and tumorigenicity, and JAK1 mutants were reported to stimulate the phosphorylation of wild-type STAT3. ${ }^{147}$ RNA sequencing identified the new fusion tyrosine kinase genes NFKB2-ROS1, NCOR2-ROS1, NFKB2TYK2, and PABPC4-TYK2, which were mutually exclusive of JAK1/STAT3 mutations, and activated the JAK/STAT3 pathway as well as ALK fusions. ${ }^{147,148}$ STAT3-mediated oncogenic mechanisms may be shared by both ALK-positive and -negative ALCLs; therefore, JAK/STAT pathway inhibitors, such as ruxolitinib, may have applications in the treatment of ALCLs. ${ }^{149}$

Among73 ALK-negative ALCLs, 22 (30\%) and six (8\%) had rearrangements at DUSP22/IRF4 (6p25.3) and TP63 (3q28) loci, respectively. ${ }^{150}$ The two events were mutually exclusive and were not observed in ALK-positive ALCL. ${ }^{150}$ These rearrangements are regarded as prognostic factors; ALK-negative ALCLs with rearrangements at the DUSP22/ IRF4 locus had good prognoses comparable with ALKpositive ALCLs, whereas those with rearrangements at the TP63 locus had poorer outcomes. ${ }^{150}$

Oncogenic truncated Erb-B2 receptor tyrosine kinase 4 (ERBB4) was expressed in $24 \%$ of ALK-negative ALCL, but not in ALK-positive ALCL or PTCL-NOS. ${ }^{151}$ ERBB4positive cases recurrently exhibited a Hodgkin-like morphology with prognoses typical of ALK-negative ALCL. ${ }^{151}$ Preliminary data suggest ERBB4 expression may be mutually exclusive of TP63, DUSP22/IRF4, ROS1, and $T Y K 2$ rearrangements, indicative of the presence of an ERBB4-positive subgroup, although further validation studies are required. ${ }^{151}$

\section{PROGNOSIS AND PROGNOSTIC FACTORS}

ALK-positive ALCL has been reported to have a better prognosis than ALK-negative ALCL or other PTCL. ${ }^{9-}$ 11,13,14,16,152,153 The long-term overall survival (OS) rates were $70-90 \%$ in patients with ALK-positive ALCL and $40-60 \%$ in patients with ALK-negative ALCL. ${ }^{9-14,16}$ Although these findings do not challenge the concept that ALK-positive ALCL is a distinct disease entity, several research groups have discussed the prognostic importance of ALK status over age in patients with systemic ALCL. In two retrospective studies analyzing a relatively large number of cases, ${ }^{12,14}$ ALK expression was not identified as an independent prognostic factor in multivariate analysis mainly because of the correlation between younger age and ALK positivity. One of the studies demonstrated that ALK expression is a prognostic factor only in patients older than 40 years. ${ }^{14}$ In the report of the IPTL project, when the comparison of ALK-positive and -negative patients was limited to those at least 40 years old or those less than 40 years old, no significant difference in failure-free survival or OS was found. ${ }^{9}$ Furthermore, in addition to age distribution, the genetic heterogeneity of the ALK-negative ALCL cohort may have complicated the analysis of the prognostic difference between ALK-positive and -negative ALCLs. For example, the proportion of patients harboring DUSP 22 or TP63 rearrangements in the ALKnegative ALCL cohort in each study may have altered the prognostic results..$^{150}$

The International Prognostic Index (IPI) is a useful tool for predicting outcomes of ALK-positive ALCL, 9,11-13,17 similar to the Prognostic Index for PTCL-U (PIT)..${ }^{9} 14$ The IPTL project reported estimated OS rates of $90 \%, 68 \%, 23 \%$, and $33 \%$ in patients with ALK-positive ALCL with IPI scores of 0-1 (low), 2 (low-intermediate), 3 (high-intermediate), and 4-5 (high), respectively. ${ }^{9}$ Similarly, in a report on patients with ALCL treated within the Groupe d'E'tude des Lymphomes de l'Adulte (GELA) trials, 8-year OS rates were $86 \%, 66 \%, 46 \%$, and $39 \%$ in the respective groups within the entire ALCL cohort. ${ }^{14}$ Although ALK-positive ALCL is generally associated with a good prognosis, it should be noted that outcomes in patients with ALK-positive ALCL having IPI scores of 3 or more are rather poor and similar to those of patients with other types of PTCL (5-year progression-free survival $[\mathrm{PFS}]$ of $20-30 \%)^{9,14,23}$

Among morphological variants, patients with the small cell variant, who often present with disseminated disease, may not have favorable outcomes, similar to those of patients with other ALK-positive ALCLs. ${ }^{5}$ With regard to the clinical impact of the difference in partner genes of $A L K$, no significant differences in prognosis have been observed for 
NPM-ALK and other translocations in ALK-positive ALCL, ${ }^{12,154}$ although the prognosis of ALK-positive large B-cell lymphoma (LBCL) differs depending on the $A L K$ fusion partner. ${ }^{43}$ In addition, some case reports have described patients with ALK-positive ALCL with concurrent rearrangement of $M Y C$ and aggressive clinical behavior. ${ }^{155,156}$

Some additional factors have been suggested to predict poor outcomes in patients with systemic ALCL, including CD56 expression, ${ }^{12}$ elevated pretreatment serum soluble CD30 levels, ${ }^{157}$ and beta-2-microglobulin $(\geq 3 \mathrm{mg} / \mathrm{L}) .{ }^{14}$ Anemia or more than 1 extranodal site of involvement have also been reported to be prognostic in patients with ALKpositive ALCL in some studies. ${ }^{9,14}$ In pediatric patients with NPM-ALK-positive ALCL, a risk stratification model using minimal disseminated disease (MDD) in bone marrow or peripheral blood detected by RT-PCR for NPM-ALK fusion and anti-ALK antibody titers in plasma was proposed. ${ }^{158}$ Both MDD (detected at diagnosis) and minimal residual disease detected during treatment have been demonstrated to have prognostic value. ${ }^{159,160}$

\section{CONVENTIONAL THERAPIES First-line therapy}

No randomized trials focusing on adult ALK-positive ALCL or both types of ALCLs have been reported. Therefore, the data are limited to those from retrospective analyses or subgroup analyses of previously conducted trials. In addition, data from the era in which the definitions of ALCL or ALK-positive ALCL had not been established should be interpreted carefully because they tend to include patients with Hodgkin lymphoma or ALK-positive LBCL. Some groups conducted prospective studies on pediatric patients. ${ }^{19,161-166}$ The pediatric data have been thoroughly reviewed elsewhere. ${ }^{18}$ Thus, in this review, we will focus on therapeutic approaches for adult patients.

Generally, patients with ALK-positive ALCL are treated with anthracycline-based regimens, such as combination cyclophosphamide, doxorubicin, vincristine, and prednisolone (CHOP) or CHOEP (CHOP plus etoposide), which provide a favorable prognosis, except for those with multiple IPI factors. For patients with limited stages, six cycles of CHOP/CHOP-like chemotherapy or 3-4 cycles of this therapy plus localized radiotherapy are generally recommended. A retrospective study evaluating doxorubicin-based chemotherapy in combination with radiotherapy in early-stage ALCL reported favorable outcomes in patients with ALKpositive ALCL (5-year OS rate, 92.9\%; 5-year PFS rate, 69.2\%). ${ }^{167}$ In contrast, another retrospective study that analyzed the survival of patients with limited stage PTCLs found no significant benefit in patients who underwent consolidative radiotherapy. ${ }^{168}$ A specific analysis on patients with ALCL was not performed in this study. Similar results have been reported in an analysis of Swedish registry data on patients with PTCL. ${ }^{17}$ Among 118 patients with stage I/II PTCL, including ALCL, 32 cases received consolidative local radiotherapy at a median dose of $40 \mathrm{~Gy}$. A trend of superior survival in patients who underwent irradiation was observed, but no risk reduction associated with the addition of radiotherapy was found by multivariate analysis. Survival data of patients treated with 3 or 4 courses of CHOP/CHOEP plus radiotherapy and those treated with at least six courses without radiotherapy were not significantly different. Although the number of cases analyzed was small in each study, and no apparent conclusions were reached, there was no definitive evidence demonstrating the benefit of combined or consolidative radiotherapy for patients with limited-stage ALK-positive ALCL. In patients who cannot tolerate multiple courses of chemotherapy, however, abbreviated CHOP combined with radiotherapy may be a reasonable choice.

For adult patients with advanced ALK-positive ALCL, six cycles of CHOP or CHOP-like regimens are generally recommended. The results of major retrospective studies are summarized in Table 3 with information on first-line treatments for patients with ALK-positive ALCL. For PTCLs, some studies have examined the effects of intensified regimens, such as hyper-CVAD/MA (cyclophosphamide, vincristine, doxorubicin, and dexamethasone/methotrexate and cytarabine), ACVBP (doxorubicin, cyclophosphamide, vindesine, bleomycin, and prednisone), or VIP-reinforced-ABVD (etoposide, ifosfamide, cisplatin alternating with doxorubicin, bleomycin, vinblastine, dacarbazine), to improve outcomes. Specific analyses of ALK-positive ALCL and ALCL have not been performed, and obvious benefits of intensification of the therapy have not been observed for PTCLs. ${ }^{13,14,153,169,170}$ Adding etoposide to CHOP may improve the prognosis of a subset of patients with PTCL. A report of patients with PTCL, including 78 ALK-positive ALCL and 113 ALKnegative ALCL, treated within the trials of the German HighGrade Non-Hodgkin Lymphoma Study Group (DSHNHL) found that the addition of etoposide to CHOP was associated with improved 3-year event-free survival (EFS; $91.2 \%$ versus $57.1 \%$ ) in patients with ALK-positive ALCL who were younger than 60 years old and with LDH of less than or equal to the upper normal value, although OS was not significantly different and adjustment with IPI or other factors was not performed. ${ }^{13}$ The value of adding etoposide to CHOP/ CHOP-like regimens in ALK-positive ALCL still needs to be evaluated in further studies.

For patients with PTCL at a high risk of relapse, consolidative high-dose chemotherapy followed by autologous stem cell transplantation (ASCT) for the first complete response (CR) has been evaluated for improvement of outcomes. ${ }^{170-173}$ Currently, the role of consolidation therapy in ALCL is controversial. A prospective study to evaluate upfront ASCT in patients with PTCL $(\mathrm{N}=62)$ included 19 patients with ALKpositive ALCL. ${ }^{174}$ In an intent-to-treat analysis, $74 \%$ of the entire cohort completed the program. A separate analysis for patients with ALK-positive ALCL demonstrated a 12-year OS and EFS of 62 and 54\%, respectively. In one retrospective study focusing on newly diagnosed ALCL treated with the combination of carmustine, etoposide, cytarabine, and melphalan (BEAM), and ASCT $(\mathrm{N}=15)$, seven of 12 patients with T/null type had ALK-positive ALCL. ${ }^{175}$ All 


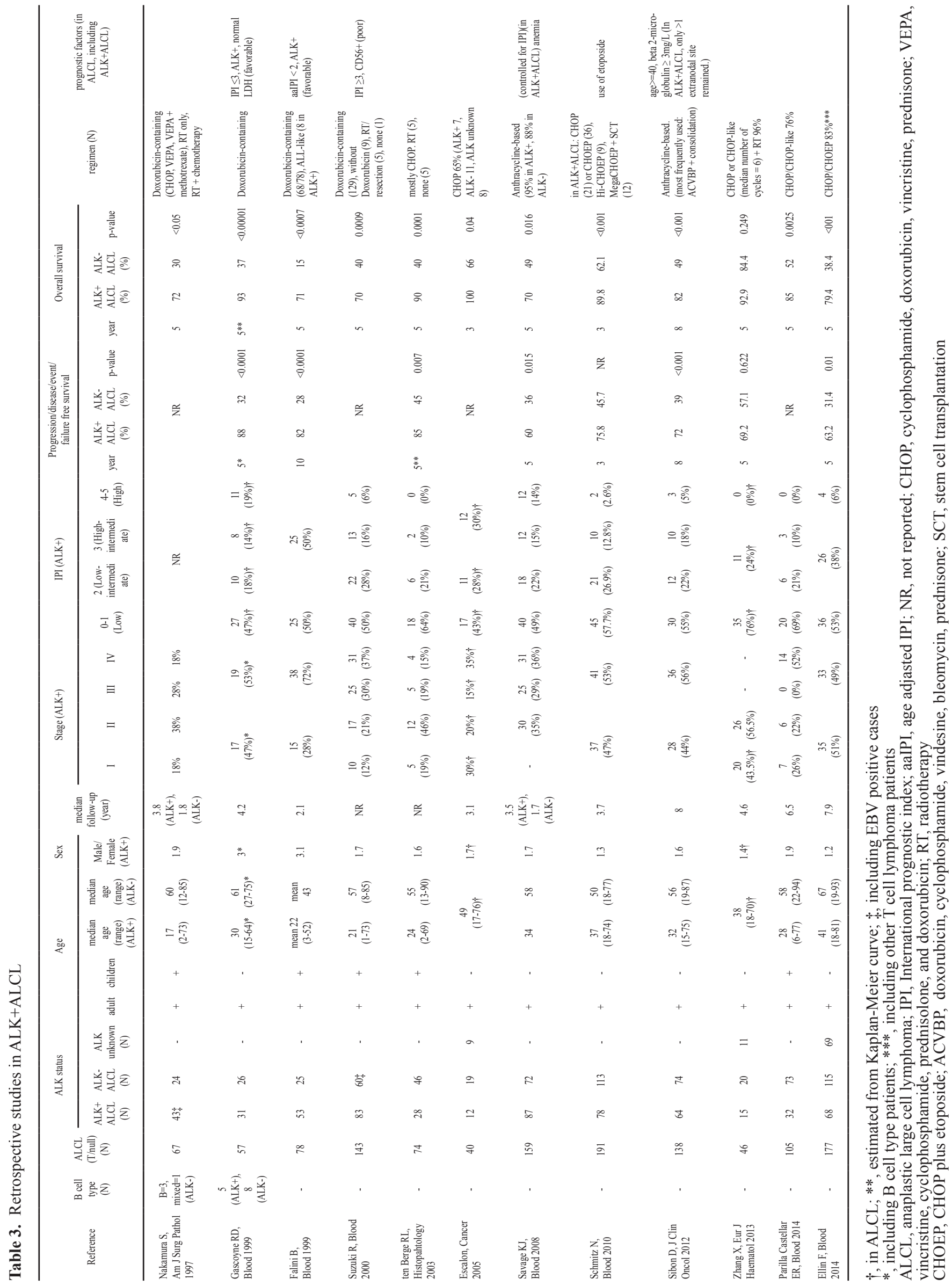


patients achieved CR, and the 5-year EFS was $87 \%$ for the entire cohort. However, it is not clear whether ASCT improved outcomes because all but two patients had low or low-intermediate IPI risk. A number of other retrospective studies examined the benefit of ASCT in the frontline setting and reported good outcomes in PTCL, including ALCL. Notably, these results should be interpreted carefully because the number of analyzed patients was small, and selection bias was an issue. ${ }^{176,177}$ In general, upfront ASCT is not included in the standard therapeutic approach for patients with ALKpositive ALCL.

\section{Therapy for refractory or relapsed cases}

Relapses are not uncommon (30\% of cases), and ASCT after salvage chemotherapy has been widely applied for patients with relapsed ALCL. Although evidence from randomized trials is lacking, ASCT or allogeneic stem cell transplantation (SCT) may provide long-term survival benefits in patients who respond to salvage therapy. There are multiple retrospective reports of ASCT in patients with relapsed/ refractory PTCL, which have been exhaustively reviewed elsewhere. ${ }^{176,177}$ Briefly, the long-term PFS rate has been reported to be $25-75 \%$, and some studies have demonstrated that the salvage rate is similar to that of DLBCL, particularly for ALCL. ${ }^{23}$ However, data on transplantation in ALKpositive ALCL is scarce. The following are the examples of studies that included patients with relapsed/refractory ALCL. In one retrospective study, patients with ALCL had a better 3 -year EFS than patients with other PTCLs (67\% versus $37 \%$, respectively). ${ }^{178}$ Another retrospective study with 28 patients with PTCL reported that patients with ALCL had a superior 3-year OS compared with patients having other PTCLs ( $86 \%$ versus 47\%, respectively), and ALK-positive ALCL was associated with a better EFS than ALK-negative ALCL (100\% versus 0\%, respectively). ${ }^{179}$ An analysis of data from the Center for International Blood and Marrow Transplantation Research (CIBMTR) database demonstrated that 39 patients with ALCL who underwent ASCT beyond CR 1 had 3-year PFS and OS rates of $50 \%$ and $65 \%$, respectively. ${ }^{180}$

Data on allogeneic SCT for relapsed/refractory ALCL are very limited. The $2-5$-year PFS rate is $30-60 \%$, with a treatment-related mortality rate of approximately $30 \%$ in selected patients. ${ }^{176}$ In an analysis of data from the CIBMTR database, 51 patients with ALCL (for whom information on ALK status is lacking) who received allogeneic SCT were identified, and the 3-year PFS and OS rates were 35 and $41 \%$, respectively, with non-relapse mortality of $31 \% .{ }^{180}$ Another retrospective study analyzed 77 recipients of allogeneic SCT who had PTCLs, including 27 with ALCL, and at least eight of these had ALK-positive ALCL. Although heavily treated patients were not included, some benefit was demonstrated for patients with chemorefractory PTCL (5-year OS of 29\%). ${ }^{181}$

For both transplant-eligible and -ineligible patients with ALCL, the discovery of novel agents, including belinostat, pralatrexate, and romidepsin, has changed the standard therapeutic approach. The following two targeted therapies have attracted much attention.

\section{TARGETED THERAPIES WITH NEW AGENTS Brentuximab vedotin}

Owing to its high expression on tumor cells and limited expression in normal tissues, CD30 has become an attractive target for antibody-based immunotherapy, particularly for Hodgkin lymphoma and ALCL. ${ }^{182}$ Brentuximab vedotin (BV) is an antibody-drug conjugate containing an anti-CD30 monoclonal antibody (cAC10) linked to the synthetic antimitotic agent monomethyl auristatin E (MMAE) via a protease cleavable dipeptide linker. In CD30-positive cells, the conjugate is internalized through receptor-mediated endocytosis, and MMAE is released by lysosomal proteases such as cathepsin B. ${ }^{183-185}$ The antitumor activity of BV has been confirmed in preclinical models, including xenograft mouse models with tumors derived from Karpas 299 cells, a cell line harboring the NPM-ALK fusion. ${ }^{186}$

Clinically, several early phase studies have reported excellent results using BV. In a phase I study for relapsed or refractory CD30-positive lymphomas, two patients with ALK-positive ALCL were evaluated, and both achieved CR. The durations of response were 17.3 and 5.0 months in the two patients. ${ }^{187}$ Another phase I study enrolled five patients with relapsed or refractory ALCL, including one patient with ALK-positive ALCL. The CR rate was 80\% (4/5) in ALCL patients; one patient who received the lowest dose of BV achieved only stable disease (SD). ${ }^{188}$ Subsequently, a multinational, open-label phase II study for relapsed or refractory systemic ALCL was conducted, and 58 patients were treated (16 patients were positive for ALK). The overall response rate (ORR) was $86 \%$ (CR rate, $57 \%$ ) for the entire cohort and $81 \%$ (CR rate; 69\%) for patients with ALK-positive ALCL. The median duration of response was 12.6 months, and the median PFS was 13.3 months, with no significant difference between ALK-positive and -negative patients. ${ }^{189}$ In terms of treatment-emergent adverse events, peripheral sensory neuropathy (PSN) was most commonly observed (24/58, 41\%), including seven (12\%) patients with grade 3 disease. BV received accelerated approval from the US Food and Drug Administration in 2011 for the treatment of relapsed or refractory Hodgkin lymphoma and systemic ALCL based on the results of two phase II studies, including the above study. Follow-up data at 3 and 4 years have been published, ${ }^{190}$ and with a median observation time of 46.3 months, and $62 \%$ (36/58) of patients were alive at the last follow-up. The estimated 4-year survival rate was $64 \%$. The median PFS was 20.0 months for all patients and 25.5 months for patients with ALK-positive ALCL. Notably, 47\% (17/36) of patients with $\mathrm{CR}$, including seven without further treatment, remained in follow-up with no evidence of progression. This suggested that BV had curative effects in some patients, although further studies are needed to confirm these findings. In Japan, a phase $1 / 2$ study was performed, and similar results were obtained. ${ }^{191}$ Retreatment with BV for relapsed CD30+ lymphomas (21 Hodgkin lymphoma and eight ALCL) has been 
evaluated in a phase II study, and the ORR in patients with ALCL was $88 \% .{ }^{192}$

BV was also tested in the initial treatment of ALCL. Fanale et al. reported a phase I study conducted in the US and Europe. Thirty-nine patients with CD30-positive T-cell lymphoma, mostly ALCL, were enrolled and received one of two regimens: a sequential treatment (two courses of BV followed by six cycles of CHOP) or a combination treatment (six cycles of BV plus CHP). In the latter regimen, vincristine was omitted due to an overlapping adverse effect (PSN) with BV. Responders could receive additional BV for 8-10 cycles. Among 32 patients with ALCL, six (19\%) had ALKpositive ALCL and were at intermediate risk (IPI 2-3). The ORRs were $85 \%(\mathrm{CR}, 62 \%)$ and $100 \%(\mathrm{CR}, 88 \%)$ in the sequential and combination groups, respectively. In the combination group, the estimated 1-year PFS rate was 71\% without consolidative ASCT. PSN (69\%) was the most frequently experienced adverse event, and grade $3 / 4$ events were experienced by $73 \%$ of patients; febrile neutropenia (31\%), neutropenia (23\%), anemia (15\%), and pulmonary embolism (12\%) occurred in at least $10 \%$ of patients. Based on the observations in this study, a phase III randomized study comparing $\mathrm{CHOP}$ and $\mathrm{BV}+\mathrm{CHP}$ in CD30-positive T-cell lymphomas was planned and is now ongoing (ECHELON-2, NCT01777152).

\section{ALK inhibitors}

ALK inhibitors have already been used in the treatment of $A L K$-rearranged non-small cell lung cancer. ${ }^{193,194}$ Some in vitro and in vivo studies have demonstrated that inhibition of ALK suppresses tumor growth in ALK-positive ALCL. ${ }^{195-197}$ Crizotinib was confirmed to be effective in an ALK-positive ALCL xenograft model. ${ }^{198}$ Although data regarding the efficacy of ALK inhibitors in patients with ALK-positive ALCL are still limited, encouraging results have been obtained.

Including the first report of two patients with relapsed ALK-positive ALCL who achieved a rapid CR using crizotinib, ${ }^{199}$ several case reports and studies with small numbers of heavily pretreated patients have been published (Table 4). ${ }^{200-206}$ In a pediatric phase I trial evaluating crizotinib for refractory solid tumors or ALCL, seven of nine (78\%) patients with ALK-positive ALCL achieved CR. ${ }^{207}$ Gambacorti-Passerini et al. reported nine adult patients with refractory ALK-positive ALCL treated with crizotinib. ${ }^{201}$ All patients obtained response, and, at the time of the report, four of the patients were on crizotinib and in CR without stem cell transplantation (duration of response: $>21,>30,>35$, and $>$ 40 months). The estimated 2-year PFS and OS rates were $63.7 \%$ and $72.7 \%$, respectively. A preliminary report of a phase I study (NCT01121588) had a good objective response rate $(60 \%$; five CRs and four partial responses) for pretreated ALK-positive lymphomas (14 ALK-positive ALCL and one $\mathrm{ALK}+\mathrm{LBCL})$ at a median duration of treatment of 33 weeks. ${ }^{208}$ Recently, abrupt relapses following discontinuation of crizotinib in patients who were in CR with crizotinib for 1 year or 4 years were reported. ${ }^{209}$ The appropriate timing to discontinue ALK inhibitors in responding patients is still unclear.

Ceritinib is a second-generation ALK inhibitor that has greater potency than crizotinib in vitro and has been reported to have strong antitumor effects in an ALK-positive ALCL xenograft model. ${ }^{210}$ Moreover, ceritinib has been shown to be effective in patients with crizotinib-resistant NSCLC. ${ }^{211}$ In a phase I trial evaluating ceritinib in patients with advanced or metastatic ALK-altered tumors (ASCEND-1), three patients with relapsed ALK-positive ALCL were enrolled. ${ }^{21}$ Two achieved CR, and one had partial response with maximal tumor reduction of $94.8 \%$. All three patients had maintenance of CR or partial response longer than 20 months. ${ }^{212}$

A number of trials evaluating ALK inhibitors are ongoing. The Children's Oncology Group is conducting a randomized phase II study to evaluate the feasibility and efficacy of combining BV or crizotinib with multi-agent chemotherapy (ALCL99 regimen) in pediatric newly diagnosed stage II to IV ALK-positive ALCL (NCT01979536). ${ }^{213}$ Another randomized trial with risk stratification by minimal disseminated disease and anti-ALK antibody titers ${ }^{158}$ is ongoing. The ALCL99 regimen with crizotinib or vinblastine will be evaluated in combination. ${ }^{213}$ In addition to crizotinib and ceritinib, alectinib is also in clinical evaluation for ALKpositive ALCL in Japan. Alectinib is a potent second-generation ALK inhibitor that is effective even in NSCLC harboring crizotinib-resistance mutations ${ }^{214}$ and has demonstrated promising results in clinical settings. ${ }^{215,216}$ Ongoing clinical trials for ALK-positive ALCL are listed in Table 5.

\section{ACKNOWLEDGMENTS}

NT (History, Epidemiology and etiology, Histopathology, and Immunophenotype other than CD30 and ALK), KS (Clinical features, Prognosis, Prognostic factors, Conventional therapies, and Targeted therapies with new agents), SS (CD30 and ALK), and AD (Other molecular alterations) wrote the manuscript drafts. KT edited the sections and organized them into the review article.

\section{CONFLICT OF INTEREST}

The authors do not have any conflicts of interest to declare.

\section{REFERENCES}

1 Stein H, Mason D Y, Gerdes J, O'Connor N, Wainscoat J, et al.: The expression of the Hodgkin's disease associated antigen $\mathrm{Ki}-1$ in reactive and neoplastic lymphoid tissue: evidence that Reed-Sternberg cells and histiocytic malignancies are derived from activated lymphoid cells. Blood 66: 848-858, 1985

2 Stansfeld A G, Diebold J, Noel H, Kapanci Y, Rilke F, et al.: Updated Kiel classification for lymphomas. Lancet 1: 292-293, 1988

3 Falini B, Pileri, S, Pizzolo G, Durkop H, Flenghi L, et al.: CD30 (Ki-1) molecule: a new cytokine receptor of the tumor 


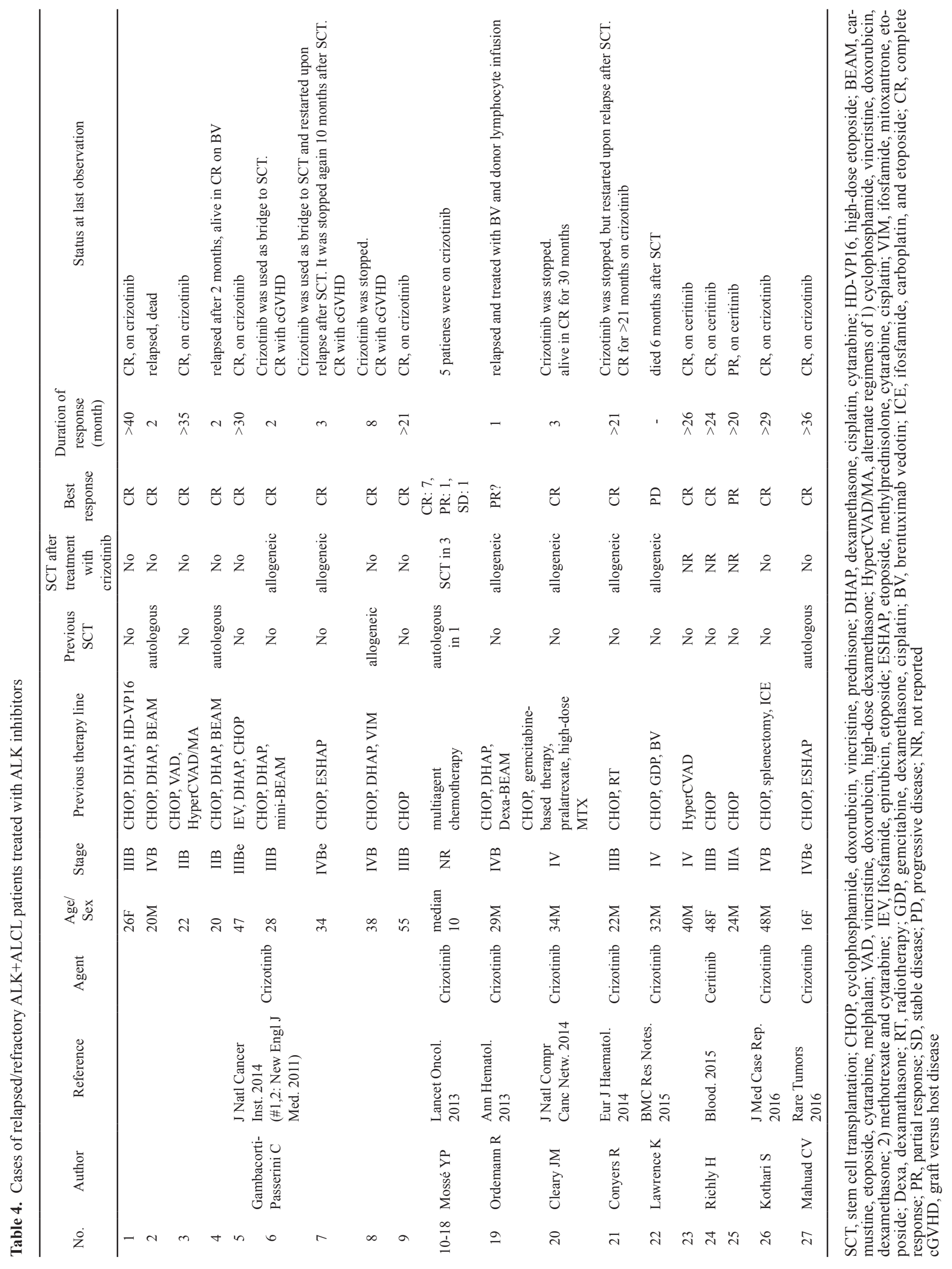




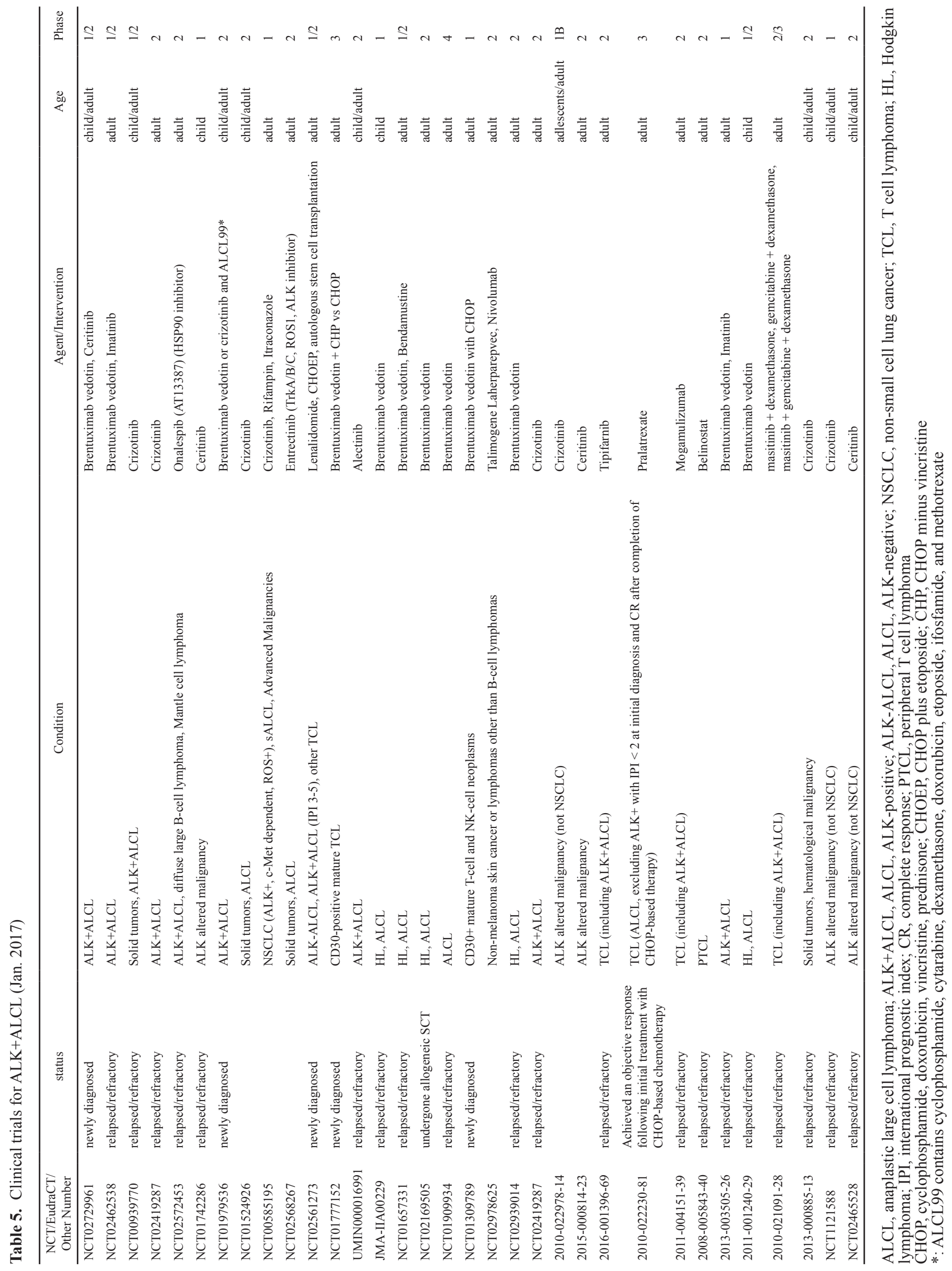


necrosis factor receptor superfamily as a tool for diagnosis and immunotherapy. Blood 85: 1-14, 1995

4 Harris N L, Jaffe E S, Stein H, Banks P M, Chan J K, et al.: A revised European-American classification of lymphoid neoplasms: a proposal from the International Lymphoma Study Group. Blood 84: 1361-1392, 1994

5 Swerdlow S H, Campo E, Harris N L, Jaffe E S, Pileri S A, Stein H, Thiele J, Vardiman J W: WHO Classification of Tumours of Haematopoietic and Lymphoid Tissues. Fourth Edition, 2008

6 Project T N -H s L C: A clinical evaluation of the International Lymphoma Study Group classification of non-Hodgkin's lymphoma. The Non-Hodgkin's Lymphoma Classification Project. Blood 89: 3909-3918, 1997

7 Vose J, Armitage J, Weisenburger D, International T C L P: International peripheral T-cell and natural killer/T-cell lymphoma study: pathology findings and clinical outcomes. J Clin Oncol 26: 4124-4130, 2008

8 Lamant L, Pileri S, Sabattini E, Brugieres L, Jaffe E S, et al.: Cutaneous presentation of ALK-positive anaplastic large cell lymphoma following insect bites: evidence for an association in five cases. Haematologica 95: 449-455, 2010

9 Savage K J, Harris N L, Vose J M, Ullrich F, Jaffe E S, et al.: ALK- anaplastic large-cell lymphoma is clinically and immunophenotypically different from both ALK + ALCL and peripheral T-cell lymphoma, not otherwise specified: report from the International Peripheral T-Cell Lymphoma Project. Blood 111: 5496-5504, 2008

10 Falini B, Pileri S, Zinzani P L, Carbone A, Zagonel V, et al.: $\mathrm{ALK}+$ lymphoma: clinico-pathological findings and outcome. Blood 93: 2697-2706, 1999

11 Gascoyne R D, Aoun P, Wu D, Chhanabhai M, Skinnider B F, et al.: Prognostic significance of anaplastic lymphoma kinase (ALK) protein expression in adults with anaplastic large cell lymphoma. Blood 93: 3913-3921, 1999

12 Suzuki R, Kagami Y, Takeuchi K, Kami M, Okamoto M, et al.: Prognostic significance of CD56 expression for ALK-positive and ALK-negative anaplastic large-cell lymphoma of T/null cell phenotype. Blood 96: 2993-3000, 2000

13 Schmitz N, Trumper L, Ziepert M, Nickelsen M, Ho A D, et al.: Treatment and prognosis of mature T-cell and NK-cell lymphoma: an analysis of patients with T-cell lymphoma treated in studies of the German High-Grade Non-Hodgkin Lymphoma Study Group. Blood 116: 3418-3425, 2010

14 Sibon D, Fournier M, Briere J, Lamant L, Haioun C, et al.: Long-term outcome of adults with systemic anaplastic large-cell lymphoma treated within the Groupe d'Etude des Lymphomes de l'Adulte trials. J Clin Oncol 30: 3939-3946, 2012

15 Benharroch D, Meguerian-Bedoyan Z, Lamant L, Amin C, Brugieres L, et al.: ALK-positive lymphoma: a single disease with a broad spectrum of morphology. Blood 91: 2076-2084, 1998

16 ten Berge R L, de Bruin P C, Oudejans J J, Ossenkoppele G J, van der Valk $\mathrm{P}$, et al.: ALK-negative anaplastic large-cell lymphoma demonstrates similar poor prognosis to peripheral T-cell lymphoma, unspecified. Histopathology 43: 462-469, 2003

17 Ellin F, Landstrom J, Jerkeman M, Relander T: Real-world data on prognostic factors and treatment in peripheral T-cell lymphomas: a study from the Swedish Lymphoma Registry. Blood 124: 1570-1577, 2014

18 Eyre T A, Khan D, Hall G W, Collins G P: Anaplastic lymphoma kinase-positive anaplastic large cell lymphoma: current and future perspectives in adult and paediatric disease. Eur J Haematol 93: 455-468, 2014

19 Brugieres L, Deley M C, Pacquement H, Meguerian-Bedoyan $\mathrm{Z}$, Terrier-Lacombe M J, et al.: CD30(+) anaplastic large-cell lymphoma in children: analysis of 82 patients enrolled in two consecutive studies of the French Society of Pediatric Oncology. Blood 92: 3591-3598, 1998

20 Fraga M, Brousset P, Schlaifer D, Payen C, Robert A, et al.: Bone marrow involvement in anaplastic large cell lymphoma. Immunohistochemical detection of minimal disease and its prognostic significance. Am J Clin Pathol 103: 82-89, 1995

21 Nomura M, Narita Y, Miyakita Y, Ohno M, Fukushima S, et al.: Clinical presentation of anaplastic large-cell lymphoma in the central nervous system. Mol Clin Oncol 1: 655-660, 2013

22 Williams D, Mori T, Reiter A, Woessman W, Rosolen A, et al.: Central nervous system involvement in anaplastic large cell lymphoma in childhood: results from a multicentre European and Japanese study. Pediatr Blood Cancer 60: E118-121, 2013

23 Hapgood G, Savage K J: The biology and management of systemic anaplastic large cell lymphoma. Blood 126: 17-25, 2015

24 Ellin F, Landstrom J, Jerkeman M, Relander T: Central nervous system relapse in peripheral T-cell lymphomas: a Swedish Lymphoma Registry study. Blood 126: 36-41, 2015

25 Bayle C, Charpentier A, Duchayne E, Manel A M, Pages M P, et al:: Leukaemic presentation of small cell variant anaplastic large cell lymphoma: report of four cases. Br J Haematol 104: 680-688, 1999

26 Kinney M C, Collins R D, Greer J P, Whitlock J A, Sioutos N, et al.: A small-cell-predominant variant of primary Ki-1 (CD30)+ T-cell lymphoma. The American journal of surgical pathology 17: 859-868, 1993

27 Chan J K, Ng C S, Hui P K, Leung T W, Lo E S, et al:: Anaplastic large cell Ki-1 lymphoma. Delineation of two morphological types. Histopathology 15: 11-34, 1989

28 Chott A, Kaserer K, Augustin I, Vesely M, Heinz R, et al.: Ki-1positive large cell lymphoma. A clinicopathologic study of 41 cases. The American journal of surgical pathology 14: 439-448, 1990

29 Nakamura S, Shiota M, Nakagawa A, Yatabe Y, Kojima M, et al.: Anaplastic large cell lymphoma: a distinct molecular pathologic entity: a reappraisal with special reference to $\mathrm{p} 80(\mathrm{NPM} /$ ALK) expression. The American journal of surgical pathology 21: 1420-1432, 1997

30 Pileri S A, Pulford K, Mori S, Mason D Y, Sabattini E, et al.: Frequent expression of the NPM-ALK chimeric fusion protein in anaplastic large-cell lymphoma, lympho-histiocytic type. Am J Pathol 150: 1207-1211, 1997

31 Falini B, Bigerna B, Fizzotti M, Pulford K, Pileri S A, et al.: ALK expression defines a distinct group of T/null lymphomas (“ALK lymphomas") with a wide morphological spectrum. Am J Pathol 153: 875-886, 1998

32 Pileri S, Falini B, Delsol G, Stein H, Baglioni P, et al.: 
Lymphohistiocytic T-cell lymphoma (anaplastic large cell lymphoma $\mathrm{CD} 30+/ \mathrm{Ki}-1+$ with a high content of reactive histiocytes). Histopathology 16: 383-391, 1990

33 Karl Lennert A C F: Histopathology of Non-Hodgkin's Lymphomas. Springer-Verlag Berlin Heidelberg, 1992

34 Ott G, Bastian B C, Katzenberger T, Decoteau J F, Kalla J, et al:: A lymphohistiocytic variant of anaplastic large cell lymphoma with demonstration of the $\mathrm{t}(2 ; 5)(\mathrm{p} 23 ; \mathrm{q} 35)$ chromosome translocation. Br J Haematol 100: 187-190, 1998

35 Pileri S, Bocchia M, Baroni C D, Martelli M, Falini B, et al.: Anaplastic large cell lymphoma (CD30 +/Ki-1+): results of a prospective clinico-pathological study of 69 cases. Br J Haematol 86: 513-523, 1994

36 Leoncini L, Del Vecchio M T, Kraft R, Megha T, Barbini P, et al:: Hodgkin's disease and CD30-positive anaplastic large cell lymphomas--a continuous spectrum of malignant disorders. A quantitative morphometric and immunohistologic study. Am J Pathol 137: 1047-1057, 1990

37 Orscheschek K, Merz H, Hell J, Binder T, Bartels H, et al.: Large-cell anaplastic lymphoma-specific translocation $(\mathrm{t}[2 ; 5]$ [p23;q35]) in Hodgkin's disease: indication of a common pathogenesis? Lancet 345: 87-90, 1995

38 MacLennan K A, Bennett M H, Tu A, Hudson B V, Easterling $\mathrm{M} \mathrm{J}$, et al.: Relationship of histopathologic features to survival and relapse in nodular sclerosing Hodgkin's disease. A study of 1659 patients. Cancer 64: 1686-1693, 1989

39 Chan J K, Buchanan R, Fletcher C D: Sarcomatoid variant of anaplastic large-cell Ki-1 lymphoma. The American journal of surgical pathology 14: 983-988, 1990

40 Delsol G, Lamant L, Mariame B, Pulford K, Dastugue N, et al.: A new subtype of large B-cell lymphoma expressing the ALK kinase and lacking the 2; 5 translocation. Blood 89: 1483-1490, 1997

41 Swerdlow S H, Campo E, Pileri S A, Harris N L, Stein H, et al.: The 2016 revision of the World Health Organization classification of lymphoid neoplasms. Blood 127: 2375-2390, 2016

42 Pan Z, Hu S, Li M, Zhou Y, Kim Y S, et al.: ALK-positive Large B-cell Lymphoma: A Clinicopathologic Study of 26 Cases With Review of Additional 108 Cases in the Literature. The American journal of surgical pathology 41: 25-38, 2017

43 Sakamoto K, Nakasone H, Togashi Y, Sakata S, Tsuyama N, et al.: ALK-positive large B-cell lymphoma: identification of EML4-ALK and a review of the literature focusing on the ALK immunohistochemical staining pattern. Int J Hematol 103: 399408, 2016

44 Horie R, Watanabe T: CD30: expression and function in health and disease. Seminars in immunology 10: 457-470, 1998

45 Gedrich R W, Gilfillan M C, Duckett C S, Van Dongen J L, Thompson C B: CD30 contains two binding sites with different specificities for members of the tumor necrosis factor receptorassociated factor family of signal transducing proteins. J Biol Chem 271: 12852-12858, 1996

46 Josimovic-Alasevic O, Durkop H, Schwarting R, Backe E, Stein $\mathrm{H}$, et al.: $\mathrm{Ki}-1$ (CD30) antigen is released by $\mathrm{Ki}-1$-positive tumor cells in vitro and in vivo. I. Partial characterization of soluble Ki-1 antigen and detection of the antigen in cell culture supernatants and in serum by an enzyme-linked immunosorbent assay. European journal of immunology 19: 157-162, 1989

47 Hansen H P, Kisseleva T, Kobarg J, Horn-Lohrens O, Havsteen, $\mathrm{B}$, et al.: A zinc metalloproteinase is responsible for the release of CD30 on human tumor cell lines. International journal of cancer 63: 750-756, 1995

48 Stein H, Gerdes J, Schwab U, Lemke H, Mason D Y, et al. Identification of Hodgkin and Sternberg-reed cells as a unique cell type derived from a newly-detected small-cell population. International journal of cancer 30: 445-459, 1982

49 Abbondanzo S L, Sato N, Straus S E, Jaffe E S: Acute infectious mononucleosis. CD30 (Ki-1) antigen expression and histologic correlations. Am J Clin Pathol 93: 698-702, 1990

50 Watanabe M, Sasaki M, Itoh K, Higashihara M, Umezawa K, et al.: JunB induced by constitutive CD30-extracellular signal-regulated kinase $1 / 2$ mitogen-activated protein kinase signaling activates the CD30 promoter in anaplastic large cell lymphoma and reed-sternberg cells of Hodgkin lymphoma. Cancer Res 65: 7628-7634, 2005

51 Hsu F Y, Johnston P B, Burke K A, Zhao Y: The expression of CD30 in anaplastic large cell lymphoma is regulated by nucleophosmin-anaplastic lymphoma kinase-mediated JunB level in a cell type-specific manner. Cancer Res 66: 9002-9008, 2006

52 Staber P B, Vesely P, Haq N, Ott R G, Funato K, et al.: The oncoprotein NPM-ALK of anaplastic large-cell lymphoma induces JUNB transcription via ERK1/2 and JunB translation via mTOR signaling. Blood 110: 3374-3383, 2007

53 Duckett C S, Gedrich R W, Gilfillan M C, Thompson C B: Induction of nuclear factor kappaB by the $\mathrm{CD} 30$ receptor is mediated by TRAF1 and TRAF2. Molecular and cellular biology 17: 1535-1542, 1997

54 Zheng B, Fiumara P, Li Y V, Georgakis G, Snell V, et al.: MEK/ ERK pathway is aberrantly active in Hodgkin disease: a signaling pathway shared by CD30, CD40, and RANK that regulates cell proliferation and survival. Blood 102: 1019-1027, 2003

55 Harlin H, Podack E, Boothby M, Alegre M L: TCR-independent CD30 signaling selectively induces IL-13 production via a TNF receptor-associated factor/p38 mitogen-activated protein kinasedependent mechanism. Journal of immunology 169: 2451-2459, 2002

56 Lee S Y, Park C G, Choi Y: T cell receptor-dependent cell death of $\mathrm{T}$ cell hybridomas mediated by the CD30 cytoplasmic domain in association with tumor necrosis factor receptor-associated factors. The Journal of experimental medicine 183: 669674, 1996

57 Telford W G, Nam S Y, Podack E R, Miller R A: CD30regulated apoptosis in murine $\mathrm{CD} 8 \mathrm{~T}$ cells after cessation of TCR signals. Cellular immunology 182: 125-136, 1997

58 Dai Z, Nasr I W, Reel M, Deng S, Diggs L, et al.: Impaired recall of CD8 memory $T$ cells in immunologically privileged tissue. Journal of immunology 174: 1165-1170, 2005

59 Chiarle R, Podda A, Prolla G, Podack E R, Thorbecke G J, et al.: $\mathrm{CD} 30$ overexpression enhances negative selection in the thymus and mediates programmed cell death via a Bcl-2sensitive pathway. Journal of immunology 163: 194-205, 1999

60 Smith C A, Gruss H J, Davis T, Anderson D, Farrah T, et al.: CD30 antigen, a marker for Hodgkin's lymphoma, is a receptor whose ligand defines an emerging family of cytokines with 
homology to TNF. Cell 73: 1349-1360, 1993

61 Hubinger G, Muller E, Scheffrahn I, Schneider C, Hildt E, et al.: CD30-mediated cell cycle arrest associated with induced expression of $\mathrm{p} 21$ (CIP1/WAF1) in the anaplastic large cell lymphoma cell line Karpas 299. Oncogene 20: 590-598, 2001

62 Mir S S, Richter B W, Duckett C S: Differential effects of CD30 activation in anaplastic large cell lymphoma and Hodgkin disease cells. Blood 96: 4307-4312, 2000

63 Wright C W, Rumble J M, Duckett C S: CD30 activates both the canonical and alternative NF-kappaB pathways in anaplastic large cell lymphoma cells. J Biol Chem 282: 10252-10262, 2007

64 Krysov S V, Rowley T F, Al-Shamkhani A: Inhibition of p38 mitogen-activated protein kinase unmasks a CD30-triggered apoptotic pathway in anaplastic large cell lymphoma cells. Mol Cancer Ther 6: 703-711, 2007

65 Iwahara T, Fujimoto J, Wen D, Cupples R, Bucay N, et al.: Molecular characterization of ALK, a receptor tyrosine kinase expressed specifically in the nervous system. Oncogene 14: 439-449, 1997

66 Beckmann G, Bork P: An adhesive domain detected in functionally diverse receptors. Trends in biochemical sciences 18 : 40-41, 1993

67 Daly N L, Scanlon M J, Djordjevic J T, Kroon P A, Smith R: Three-dimensional structure of a cysteine-rich repeat from the low-density lipoprotein receptor. Proceedings of the National Academy of Sciences of the United States of America 92: 63346338, 1995

68 Pittaluga S, Wlodarska I, Pulford K, Campo E, Morris S W, et al:: The monoclonal antibody ALK1 identifies a distinct morphological subtype of anaplastic large cell lymphoma associated with 2p23/ALK rearrangements. Am J Pathol 151: 343-351, 1997

69 Chiarle R, Voena C, Ambrogio C, Piva R, Inghirami G: The anaplastic lymphoma kinase in the pathogenesis of cancer. Nat Rev Cancer 8: 11-23, 2008

70 Yan B, Kuick C H, Lim M, Venkataraman K, Tennakoon C, et $a l$ : Platform comparison for evaluation of ALK protein immunohistochemical expression, genomic copy number and hotspot mutation status in neuroblastomas. PLoS One 9: e106575, 2014

71 Pearson J D, Lee J K, Bacani J T, Lai R, Ingham R J: NPMALK: The Prototypic Member of a Family of Oncogenic Fusion Tyrosine Kinases. J Signal Transduct 2012: 123253, 2012

72 Shiota M, Fujimoto J, Semba T, Satoh H, Yamamoto T, et al.: Hyperphosphorylation of a novel $80 \mathrm{kDa}$ protein-tyrosine kinase similar to Ltk in a human Ki-1 lymphoma cell line, AMS3. Oncogene 9: 1567-1574, 1994

73 Morris S W, Kirstein M N, Valentine M B, Dittmer K G, Shapiro D N, et al:: Fusion of a kinase gene, ALK, to a nucleolar protein gene, NPM, in non-Hodgkin's lymphoma. Science 263: 1281-1284, 1994

74 Hernandez L, Pinyol M, Hernandez S, Bea S, Pulford K, et al.: TRK-fused gene (TFG) is a new partner of ALK in anaplastic large cell lymphoma producing two structurally different TFGALK translocations. Blood 94: 3265-3268, 1999

75 Lamant L, Dastugue N, Pulford K, Delsol G, Mariame B: A new fusion gene TPM3-ALK in anaplastic large cell lymphoma created by a $(1 ; 2)(\mathrm{q} 25 ; \mathrm{p} 23)$ translocation. Blood 93: 3088-3095, 1999

76 Meech S J, McGavran L, Odom L F, Liang X, Meltesen L, et al.: Unusual childhood extramedullary hematologic malignancy with natural killer cell properties that contains tropomyosin 4--anaplastic lymphoma kinase gene fusion. Blood 98: 12091216, 2001

77 Colleoni G W, Bridge J A, Garicochea B, Liu J, Filippa D A, et al.: ATIC-ALK: A novel variant ALK gene fusion in anaplastic large cell lymphoma resulting from the recurrent cryptic chromosomal inversion, inv(2)(p23q35). Am J Pathol 156: 781-789, 2000

78 Cools J, Wlodarska I, Somers R, Mentens N, Pedeutour F, et al.: Identification of novel fusion partners of ALK, the anaplastic lymphoma kinase, in anaplastic large-cell lymphoma and inflammatory myofibroblastic tumor. Genes Chromosomes Cancer 34: 354-362, 2002

79 Touriol C, Greenland C, Lamant L, Pulford K, Bernard F, et al.: Further demonstration of the diversity of chromosomal changes involving 2p23 in ALK-positive lymphoma: 2 cases expressing ALK kinase fused to CLTCL (clathrin chain polypeptide-like). Blood 95: 3204-3207, 2000

80 Tort F, Pinyol M, Pulford K, Roncador G, Hernandez L, et al.: Molecular characterization of a new ALK translocation involving moesin (MSN-ALK) in anaplastic large cell lymphoma. Lab Invest 81: 419-426, 2001

81 Lamant L, Gascoyne R D, Duplantier M M, Armstrong F, Raghab A, et al: Non-muscle myosin heavy chain (MYH9): a new partner fused to ALK in anaplastic large cell lymphoma. Genes Chromosomes Cancer 37: 427-432, 2003

82 Feldman A L, Vasmatzis G, Asmann Y W, Davila J, Middha S, et al.: Novel TRAF1-ALK fusion identified by deep RNA sequencing of anaplastic large cell lymphoma. Genes Chromosomes Cancer 52: 1097-1102, 2013

83 Gascoyne R D, Lamant L, Martin-Subero J I, Lestou V S, Harris N L, et al.: ALK-positive diffuse large B-cell lymphoma is associated with Clathrin-ALK rearrangements: report of 6 cases. Blood 102: 2568-2573, 2003

84 Van Roosbroeck K, Cools J, Dierickx D, Thomas J, Vandenberghe $\mathrm{P}$, et al.: ALK-positive large B-cell lymphomas with cryptic SEC31A-ALK and NPM1-ALK fusions. Haematologica 95: 509-513, 2010

85 Takeuchi K, Soda M, Togashi Y, Ota Y, Sekiguchi Y, et al.: Identification of a novel fusion, SQSTM1-ALK, in ALKpositive large B-cell lymphoma. Haematologica 96: 464-467, 2011

86 Lee S E, Kang S Y, Takeuchi K, Ko Y H: Identification of RANBP2-ALK fusion in ALK positive diffuse large B-cell lymphoma. Hematol Oncol 32: 221-224, 2014

87 Chan J K, Lamant L, Algar E, Delsol G, Tsang W Y, et al.: ALK+ histiocytosis: a novel type of systemic histiocytic proliferative disorder of early infancy. Blood 112: 2965-2968, 2008

88 Maesako Y, Izumi K, Okamori S, Takeoka K, Kishimori C, et al: $\operatorname{inv}(2)(\mathrm{p} 23 \mathrm{q} 13) / \mathrm{RAN}-$ binding protein 2 (RANBP2)-ALK fusion gene in myeloid leukemia that developed in an elderly woman. Int J Hematol 99: 202-207, 2014

89 Lawrence B, Perez-Atayde A, Hibbard M K, Rubin B P, Dal 
Cin P, et al.: TPM3-ALK and TPM4-ALK oncogenes in inflammatory myofibroblastic tumors. Am J Pathol 157: 377-384, 2000

90 Bridge J A, Kanamori M, Ma Z, Pickering D, Hill D A, et al.: Fusion of the ALK gene to the clathrin heavy chain gene, CLTC, in inflammatory myofibroblastic tumor. Am J Pathol 159: 411-415, 2001

91 Debelenko L V, Arthur D C, Pack S D, Helman L J, Schrump D $\mathrm{S}$, et al.: Identification of CARS-ALK fusion in primary and metastatic lesions of an inflammatory myofibroblastic tumor. Lab Invest 83: 1255-1265, 2003

92 Debiec-Rychter M, Marynen P, Hagemeijer A, Pauwels P: ALK-ATIC fusion in urinary bladder inflammatory myofibroblastic tumor. Genes Chromosomes Cancer 38: 187-190, 2003

93 Ma Z, Hill D A, Collins M H, Morris S W, Sumegi J, et al.: Fusion of ALK to the Ran-binding protein 2 (RANBP2) gene in inflammatory myofibroblastic tumor. Genes Chromosomes Cancer 37: 98-105, 2003

94 Panagopoulos I, Nilsson T, Domanski H A, Isaksson M, Lindblom P, et al.: Fusion of the SEC31L1 and ALK genes in an inflammatory myofibroblastic tumor. International journal of cancer 118: 1181-1186, 2006

95 Takeuchi K, Soda M, Togashi Y, Sugawara E, Hatano S, et al.: Pulmonary inflammatory myofibroblastic tumor expressing a novel fusion, PPFIBP1-ALK: reappraisal of anti-ALK immunohistochemistry as a tool for novel ALK fusion identification. Clin Cancer Res 17: 3341-3348, 2011

96 Lovly C M, Gupta A, Lipson D, Otto G, Brennan T, et al.: Inflammatory myofibroblastic tumors harbor multiple potentially actionable kinase fusions. Cancer Discov 4: 889-895, 2014

97 Lee J C, Li C F, Huang H Y, Zhu M J, Marino-Enriquez A, et al: : ALK oncoproteins in atypical inflammatory myofibroblastic tumours: novel RRBP1-ALK fusions in epithelioid inflammatory myofibroblastic sarcoma. J Pathol 241: 316-323, 2017

98 Panagopoulos I, Gorunova L, Lund-Iversen M, Lobmaier I, Bjerkehagen B, et al.: Recurrent fusion of the genes FN1 and ALK in gastrointestinal leiomyomas. Mod Pathol 29: 14151423, 2016

99 Soda M, Choi Y L, Enomoto M, Takada S, Yamashita Y, et al.: Identification of the transforming EML4-ALK fusion gene in non-small-cell lung cancer. Nature 448: 561-566, 2007

100 Rikova K, Guo A, Zeng Q, Possemato A, Yu J, et al.: Global survey of phosphotyrosine signaling identifies oncogenic kinases in lung cancer. Cell 131: 1190-1203, 2007

101 Takeuchi K, Choi Y L, Togashi Y, Soda M, Hatano S, et al.: KIF5B-ALK, a novel fusion oncokinase identified by an immunohistochemistry-based diagnostic system for ALK-positive lung cancer. Clin Cancer Res 15: 3143-3149, 2009

102 Togashi Y, Soda M, Sakata S, Sugawara E, Hatano S, et al.: KLC1-ALK: a novel fusion in lung cancer identified using a formalin-fixed paraffin-embedded tissue only. PLoS One 7: e31323, 2012

103 Jung Y, Kim P, Jung Y, Keum J, Kim S N, et al.: Discovery of ALK-PTPN3 gene fusion from human non-small cell lung carcinoma cell line using next generation RNA sequencing. Genes Chromosomes Cancer 51: 590-597, 2012
104 Majewski I J, Mittempergher L, Davidson N M, Bosma A, Willems S M, et al.: Identification of recurrent FGFR3 fusion genes in lung cancer through kinome-centred RNA sequencing. J Pathol 230: 270-276, 2013

105 Hong M, Kim R N, Song J Y, Choi S J, Oh E, et al.: HIP1-ALK, a novel fusion protein identified in lung adenocarcinoma. Journal of thoracic oncology : official publication of the International Association for the Study of Lung Cancer 9: 419422, 2014

106 Choi Y L, Lira M E, Hong M, Kim R N, Choi SJ, et al.: A novel fusion of TPR and ALK in lung adenocarcinoma. Journal of thoracic oncology : official publication of the International Association for the Study of Lung Cancer 9: 563-566, 2014

107 Iyevleva A G, Raskin G A, Tiurin V I, Sokolenko A P, Mitiushkina N V, et al:: Novel ALK fusion partners in lung cancer. Cancer Lett 362: 116-121, 2015

108 Kim R N, Choi Y L, Lee M S, Lira M E, Mao M, et al.: SEC31A-ALK Fusion Gene in Lung Adenocarcinoma. Cancer research and treatment : official journal of Korean Cancer Association 48: 398-402, 2016

109 Tan D S -W, Kim D -W, Thomas M, Pantano S, Wang Y, et al.: Genetic landscape of ALK+ non-small cell lung cancer (NSCLC) patients (pts) and response to ceritinib in ASCEND-1. J Clin Oncol 34: (suppl; abstr 9064), 2016

110 Debelenko L V, Raimondi S C, Daw N, Shivakumar B R, Huang D, et al.: Renal cell carcinoma with novel VCL-ALK fusion: new representative of ALK-associated tumor spectrum. Mod Pathol 24: 430-442, 2011

111 Marino-Enriquez A, Ou W B, Weldon C B, Fletcher J A, PerezAtayde A R: ALK rearrangement in sickle cell trait-associated renal medullary carcinoma. Genes Chromosomes Cancer 50: 146-153, 2011

112 Sugawara E, Togashi Y, Kuroda N, Sakata S, Hatano S, et al.: Identification of anaplastic lymphoma kinase fusions in renal cancer: large-scale immunohistochemical screening by the intercalated antibody-enhanced polymer method. Cancer 118: 4427-4436, 2012

113 Kusano H, Togashi Y, Akiba J, Moriya F, Baba K, et al.: Two Cases of Renal Cell Carcinoma Harboring a Novel STRN-ALK Fusion Gene. The American journal of surgical pathology 40: 761-769, 2016

114 Lin E, Li L, Guan Y, Soriano R, Rivers C S, et al.: Exon array profiling detects EML4-ALK fusion in breast, colorectal, and non-small cell lung cancers. Mol Cancer Res 7: 1466-1476, 2009

115 Lipson D, Capelletti M, Yelensky R, Otto G, Parker A, et al.: Identification of new ALK and RET gene fusions from colorectal and lung cancer biopsies. Nat Med 18: 382-384, 2012

116 Stransky N, Cerami E, Schalm S, Kim J L, Lengauer C: The landscape of kinase fusions in cancer. Nature communications 5: 4846, 2014

117 Lee J, Kim H C, Hong J Y, Wang K, Kim S Y, et al.: Detection of novel and potentially actionable anaplastic lymphoma kinase (ALK) rearrangement in colorectal adenocarcinoma by immunohistochemistry screening. Oncotarget 6: 24320-24332, 2015

118 Yakirevich E, Resnick M B, Mangray S, Wheeler M, Jackson C L, et al.: Oncogenic ALK Fusion in Rare and Aggressive 
Subtype of Colorectal Adenocarcinoma as a Potential Therapeutic Target. Clin Cancer Res 22: 3831-3840, 2016

119 Ren H, Tan Z P, Zhu X, Crosby K, Haack H, et al.: Identification of anaplastic lymphoma kinase as a potential therapeutic target in ovarian cancer. Cancer Res 72: 3312-3323, 2012

120 Kelly L M, Barila G, Liu P, Evdokimova V N, Trivedi S, et al.: Identification of the transforming STRN-ALK fusion as a potential therapeutic target in the aggressive forms of thyroid cancer. Proceedings of the National Academy of Sciences of the United States of America 111: 4233-4238, 2014

121 McFadden D G, Dias-Santagata D, Sadow P M, Lynch K D, Lubitz $\mathrm{C}$, et al.: Identification of oncogenic mutations and gene fusions in the follicular variant of papillary thyroid carcinoma. The Journal of clinical endocrinology and metabolism 99: E2457-2462, 2014

122 Cancer Genome Atlas Research N: Integrated genomic characterization of papillary thyroid carcinoma. Cell 159: 676-690, 2014

123 Ji J H, Oh Y L, Hong M, Yun J W, Lee H W, et al.: Identification of Driving ALK Fusion Genes and Genomic Landscape of Medullary Thyroid Cancer. PLoS genetics 11: e1005467, 2015

124 Perot G, Soubeyran I, Ribeiro A, Bonhomme B, Savagner F, et al.: Identification of a recurrent STRN/ALK fusion in thyroid carcinomas. PLoS One 9: e87170, 2014

125 Wiesner T, He J, Yelensky R, Esteve-Puig R, Botton T, et al.: Kinase fusions are frequent in Spitz tumours and spitzoid melanomas. Nature communications 5: 3116, 2014

126 Yeh I, de la Fouchardiere A, Pissaloux D, Mully T W, Garrido M C, et al.: Clinical, histopathologic, and genomic features of Spitz tumors with ALK fusions. The American journal of surgical pathology 39: 581-591, 2015

127 Grisendi S, Mecucci C, Falini B, Pandolfi P P: Nucleophosmin and cancer. Nat Rev Cancer 6: 493-505, 2006

128 Tort F, Campo E, Pohlman B, Hsi E: Heterogeneity of genomic breakpoints in MSN-ALK translocations in anaplastic large cell lymphoma. Hum Pathol 35: 1038-1041, 2004

129 Martelli M P, Sozzi G, Hernandez L, Pettirossi V, Navarro A, et al.: EML4-ALK rearrangement in non-small cell lung cancer and non-tumor lung tissues. Am J Pathol 174: 661-670, 2009

130 Takeuchi K: Interpretation of anti-ALK immunohistochemistry results. Journal of thoracic oncology : official publication of the International Association for the Study of Lung Cancer 8: e6768, 2013

131 Takamochi K, Takeuchi K, Hayashi T, Oh S, Suzuki K: A rational diagnostic algorithm for the identification of ALK rearrangement in lung cancer: a comprehensive study of surgically treated Japanese patients. PLoS One 8: e69794, 2013

132 Corao D A, Biegel J A, Coffin C M, Barr FG, Wainwright L M, et al: ALK expression in rhabdomyosarcomas: correlation with histologic subtype and fusion status. Pediatr Dev Pathol 12: 275-283, 2009

133 Foss H D, Anagnostopoulos I, Araujo I, Assaf C, Demel G, et al.: Anaplastic large-cell lymphomas of T-cell and null-cell phenotype express cytotoxic molecules. Blood 88: 4005-4011, 1996

134 Herbst H, Tippelmann G, Anagnostopoulos I, Gerdes J, Schwarting R, et al.: Immunoglobulin and T-cell receptor gene rearrangements in Hodgkin's disease and Ki-1-positive anaplastic large cell lymphoma: dissociation between phenotype and genotype. Leuk Res 13: 103-116, 1989

135 O'Connor N T, Stein H, Gatter K C, Wainscoat J S, Crick J, et al.: Genotypic analysis of large cell lymphomas which express the Ki-1 antigen. Histopathology 11: 733-740, 1987

136 Krenacs L, Wellmann A, Sorbara L, Himmelmann A W, Bagdi E, et al.: Cytotoxic cell antigen expression in anaplastic large cell lymphomas of T- and null-cell type and Hodgkin's disease: evidence for distinct cellular origin. Blood 89: 980-989, 1997

137 Delsol G, Al Saati T, Gatter K C, Gerdes J, Schwarting R, et al.: Coexpression of epithelial membrane antigen (EMA), Ki-1, and interleukin-2 receptor by anaplastic large cell lymphomas. Diagnostic value in so-called malignant histiocytosis. Am J Pathol 130: 59-70, 1988

138 Rosso R, Paulli M, Magrini U, Kindl S, Boveri E, et al.: Anaplastic large cell lymphoma, CD30/Ki-1 positive, expressing the CD15/Leu-M1 antigen. Immunohistochemical and morphological relationships to Hodgkin's disease. Virchows Arch A Pathol Anat Histopathol 416: 229-235, 1990

139 Falini B, Flenghi L, Pileri S, Gambacorta M, Bigerna B, et al.: PG-M1: a new monoclonal antibody directed against a fixativeresistant epitope on the macrophage-restricted form of the CD68 molecule. Am J Pathol 142: 1359-1372, 1993

140 Feldman A L, Law M E, Inwards D J, Dogan A, McClure R F, et al:: PAX5-positive T-cell anaplastic large cell lymphomas associated with extra copies of the PAX5 gene locus. Mod Pathol 23: 593-602, 2010

141 Bonzheim I, Geissinger E, Roth S, Zettl A, Marx A, et al.: Anaplastic large cell lymphomas lack the expression of T-cell receptor molecules or molecules of proximal T-cell receptor signaling. Blood 104: 3358-3360, 2004

142 Ambrogio C, Martinengo C, Voena C, Tondat F, Riera L, et al.: NPM-ALK oncogenic tyrosine kinase controls T-cell identity by transcriptional regulation and epigenetic silencing in lymphoma cells. Cancer Res 69: 8611-8619, 2009

143 Hassler M R, Pulverer W, Lakshminarasimhan R, Redl E, Hacker J, et al.: Insights into the Pathogenesis of Anaplastic Large-Cell Lymphoma through Genome-wide DNA Methylation Profiling. Cell Rep 17: 596-608, 2016

144 Lamant L, de Reynies A, Duplantier M M, Rickman D S, Sabourdy F, et al.: Gene-expression profiling of systemic anaplastic large-cell lymphoma reveals differences based on ALK status and two distinct morphologic ALK+ subtypes. Blood 109: 2156-2164, 2007

145 Weilemann A, Grau M, Erdmann T, Merkel O, Sobhiafshar U, et al.: Essential role of IRF4 and MYC signaling for survival of anaplastic large cell lymphoma. Blood 125: 124-132, 2015

146 Salaverria I, Bea S, Lopez-Guillermo A, Lespinet V, Pinyol M, et al:: Genomic profiling reveals different genetic aberrations in systemic ALK-positive and ALK-negative anaplastic large cell lymphomas. Br J Haematol 140: 516-526, 2008

147 Crescenzo R, Abate F, Lasorsa E, Tabbo F, Gaudiano M, et al.: Convergent mutations and kinase fusions lead to oncogenic STAT3 activation in anaplastic large cell lymphoma. Cancer Cell 27: 516-532, 2015

148 Abate F, Zairis S, Ficarra E, Acquaviva A, Wiggins C H, et al.: Pegasus: a comprehensive annotation and prediction tool for 
detection of driver gene fusions in cancer. BMC Syst Biol 8: 97, 2014

149 Mereu E, Pellegrino E, Scarfo I, Inghirami G, Piva R: The heterogeneous landscape of ALK negative ALCL. Oncotarget 2017

150 Parrilla Castellar E R, Jaffe E S, Said J W, Swerdlow S H, Ketterling R P, et al.: ALK-negative anaplastic large cell lymphoma is a genetically heterogeneous disease with widely disparate clinical outcomes. Blood 124: 1473-1480, 2014

151 Scarfo I, Pellegrino E, Mereu E, Kwee I, Agnelli L, et al.: Identification of a new subclass of ALK-negative ALCL expressing aberrant levels of ERBB4 transcripts. Blood 127: 221-232, 2016

152 Shiota M, Nakamura S, Ichinohasama R, Abe M, Akagi T, et al.: Anaplastic large cell lymphomas expressing the novel chimeric protein $\mathrm{p} 80 \mathrm{NPM} / \mathrm{ALK}$ : a distinct clinicopathologic entity. Blood 86: 1954-1960, 1995

153 Escalon M P, Liu N S, Yang Y, Hess M, Walker P L, et al.: Prognostic factors and treatment of patients with T-cell nonHodgkin lymphoma: the M. D. Anderson Cancer Center experience. Cancer 103: 2091-2098, 2005

154 Falini B, Pulford K, Pucciarini A, Carbone A, De Wolf-Peeters, $\mathrm{C}$, et al.: Lymphomas expressing ALK fusion protein(s) other than NPM-ALK. Blood 94: 3509-3515, 1999

155 Liang X, Branchford B, Greffe B, McGavran L, Carstens B, et $a l$ : Dual ALK and MYC rearrangements leading to an aggressive variant of anaplastic large cell lymphoma. J Pediatr Hematol Oncol 35: e209-213, 2013

156 Moritake H, Shimonodan H, Marutsuka K, Kamimura S, Kojima $\mathrm{H}$, et al.: C-MYC rearrangement may induce an aggressive phenotype in anaplastic lymphoma kinase positive anaplastic large cell lymphoma: Identification of a novel fusion gene ALO17/C-MYC. Am J Hematol 86: 75-78, 2011

157 Zinzani P L, Pileri S, Bendandi M, Buzzi M, Sabattini E, et al.: Clinical implications of serum levels of soluble CD30 in 70 adult anaplastic large-cell lymphoma patients. J Clin Oncol 16: 1532-1537, 1998

158 Mussolin L, Damm-Welk C, Pillon M, Zimmermann M, Franceschetto G, et al.: Use of minimal disseminated disease and immunity to NPM-ALK antigen to stratify ALK-positive ALCL patients with different prognosis. Leukemia 27: 416-422, 2013

159 Damm-Welk C, Mussolin L, Zimmermann M, Pillon M, Klapper W, et al.: Early assessment of minimal residual disease identifies patients at very high relapse risk in NPM-ALKpositive anaplastic large-cell lymphoma. Blood 123: 334-337, 2014

160 Damm-Welk C, Busch K, Burkhardt B, Schieferstein J, Viehmann S, et al.: Prognostic significance of circulating tumor cells in bone marrow or peripheral blood as detected by qualitative and quantitative PCR in pediatric NPM-ALK-positive anaplastic large-cell lymphoma. Blood 110: 670-677, 2007

161 Le Deley M C, Reiter A, Williams D, Delsol G, Oschlies I, et al.: Prognostic factors in childhood anaplastic large cell lymphoma: results of a large European intergroup study. Blood 111: 1560-1566, 2008

162 Williams D M, Hobson R, Imeson J, Gerrard M, McCarthy K, et al.: Anaplastic large cell lymphoma in childhood: analysis of
72 patients treated on The United Kingdom Children's Cancer Study Group chemotherapy regimens. Br J Haematol 117: 812820, 2002

163 Brugieres L, Le Deley M C, Rosolen A, Williams D, Horibe K, et al: : Impact of the methotrexate administration dose on the need for intrathecal treatment in children and adolescents with anaplastic large-cell lymphoma: results of a randomized trial of the EICNHL Group. J Clin Oncol 27: 897-903, 2009

164 Le Deley M C, Rosolen A, Williams D M , Horibe K, Wrobel $\mathrm{G}$, et al.: Vinblastine in children and adolescents with high-risk anaplastic large-cell lymphoma: results of the randomized ALCL99-vinblastine trial. J Clin Oncol 28: 3987-3993, 2010

165 Seidemann K, Tiemann M, Schrappe M, Yakisan E, Simonitsch, I, et al: : Short-pulse B-non-Hodgkin lymphoma-type chemotherapy is efficacious treatment for pediatric anaplastic large cell lymphoma: a report of the Berlin-Frankfurt-Munster Group Trial NHL-BFM 90. Blood 97: 3699-3706, 2001

166 Reiter A, Schrappe M, Tiemann M, Parwaresch R, Zimmermann $\mathrm{M}$, et al.: Successful treatment strategy for Ki-1 anaplastic large-cell lymphoma of childhood: a prospective analysis of 62 patients enrolled in three consecutive Berlin-Frankfurt-Munster group studies. J Clin Oncol 12: 899-908, 1994

167 Zhang X M, Li Y X, Wang W H, Jin J, Wang S L, et al.: Favorable outcome with doxorubicin-based chemotherapy and radiotherapy for adult patients with early stage primary systemic anaplastic large-cell lymphoma. Eur J Haematol 90: 195201, 2013

168 Briski R, Feldman A L, Bailey N G, Lim M S, Ristow K, et al.: Survival in patients with limited-stage peripheral T-cell lymphomas. Leuk Lymphoma 56: 1665-1670, 2015

169 Abramson J S, Feldman T, Kroll-Desrosiers A R, Muffly L S, Winer E, et al:: Peripheral T-cell lymphomas in a large US multicenter cohort: prognostication in the modern era including impact of frontline therapy. Ann Oncol 25: 2211-2217, 2014

170 Simon A, Peoch M, Casassus P, Deconinck E, Colombat P, et al.: Upfront VIP-reinforced-ABVD (VIP-rABVD) is not superior to $\mathrm{CHOP} / 21$ in newly diagnosed peripheral $\mathrm{T}$ cell lymphoma. Results of the randomized phase III trial GOELAMSLTP95. Br J Haematol 151: 159-166, 2010

171 d'Amore F, Relander T, Lauritzsen G F, Jantunen E, Hagberg H, et al.: Up-front autologous stem-cell transplantation in peripheral T-cell lymphoma: NLG-T-01. J Clin Oncol 30: 3093-3099, 2012

172 Nickelsen M, Ziepert M, Zeynalova S, Glass B, Metzner B, et al.: High-dose CHOP plus etoposide (MegaCHOEP) in T-cell lymphoma: a comparative analysis of patients treated within trials of the German High-Grade Non-Hodgkin Lymphoma Study Group (DSHNHL). Ann Oncol 20: 1977-1984, 2009

173 Corradini P, Vitolo U, Rambaldi A, Miceli R, Patriarca F, et al.: Intensified chemo-immunotherapy with or without stem cell transplantation in newly diagnosed patients with peripheral T-cell lymphoma. Leukemia 28: 1885-1891, 2014

174 Corradini P, Tarella C, Zallio F, Dodero A, Zanni M, et al.: Long-term follow-up of patients with peripheral T-cell lymphomas treated up-front with high-dose chemotherapy followed by autologous stem cell transplantation. Leukemia 20: 1533-1538, 2006 
175 Deconinck E, Lamy T, Foussard C, Gaillard F, Delwail V, et al.: Autologous stem cell transplantation for anaplastic large-cell lymphomas: results of a prospective trial. Br J Haematol 109: 736-742, 2000

176 Gkotzamanidou M, Papadimitriou C A: Peripheral T-cell lymphoma: the role of hematopoietic stem cell transplantation. Crit Rev Oncol Hematol 89: 248-261, 2014

177 Yared J, Kimball A: The role of high dose chemotherapy and autologous stem-cell transplantation in peripheral T-cell lymphoma: a review of the literature and new perspectives. Cancer Treat Rev 39: 51-59, 2013

178 Song K W, Mollee P, Keating A, Crump M: Autologous stem cell transplant for relapsed and refractory peripheral T-cell lymphoma: variable outcome according to pathological subtype. $\mathrm{Br}$ J Haematol 120: 978-985, 2003

179 Jagasia M, Morgan D, Goodman S, Hamilton K, Kinney M, et al.: Histology impacts the outcome of peripheral T-cell lymphomas after high dose chemotherapy and stem cell transplant. Leuk Lymphoma 45: 2261-2267, 2004

180 Smith S M, Burns L J, van Besien K, Lerademacher J, He W, et al.: Hematopoietic cell transplantation for systemic mature T-cell non-Hodgkin lymphoma. J Clin Oncol 31: 3100-3109, 2013

181 Le Gouill S, Milpied N, Buzyn A, De Latour R P, Vernant J P, et al.: Graft-versus-lymphoma effect for aggressive T-cell lymphomas in adults: a study by the Societe Francaise de Greffe de Moelle et de Therapie Cellulaire. J Clin Oncol 26: 2264-2271, 2008

182 Deng C, Pan B, O'Connor O A: Brentuximab vedotin. Clin Cancer Res 19: 22-27, 2013

183 Doronina S O, Toki B E, Torgov M Y, Mendelsohn B A, Cerveny C G, et al:: Development of potent monoclonal antibody auristatin conjugates for cancer therapy. Nat Biotechnol 21: 778-784, 2003

184 Sutherland M S, Sanderson R J, Gordon K A, Andreyka J, Cerveny $\mathrm{C} \mathrm{G}$, et al.: Lysosomal trafficking and cysteine protease metabolism confer target-specific cytotoxicity by peptidelinked anti-CD30-auristatin conjugates. J Biol Chem 281: 10540-10547, 2006

185 Okeley N M, Miyamoto J B, Zhang X, Sanderson R J, Benjamin D R, et al.: Intracellular activation of SGN-35, a potent anti-CD30 antibody-drug conjugate. Clin Cancer Res 16: 888-897, 2010

186 Francisco J A, Cerveny C G, Meyer D L, Mixan B J, Klussman $\mathrm{K}$, et al.: cAC10-vcMMAE, an anti-CD30-monomethyl auristatin $\mathrm{E}$ conjugate with potent and selective antitumor activity. Blood 102: 1458-1465, 2003

187 Younes A, Bartlett N L, Leonard J P, Kennedy D A, Lynch C M, et al.: Brentuximab vedotin (SGN-35) for relapsed CD30positive lymphomas. N Engl J Med 363: 1812-1821, 2010

188 Fanale M A, Forero-Torres A, Rosenblatt J D, Advani R H, Franklin A R, et al.: A phase I weekly dosing study of brentuximab vedotin in patients with relapsed/refractory CD30-positive hematologic malignancies. Clin Cancer Res 18: 248-255, 2012

189 Pro B, Advani R, Brice P, Bartlett N L, Rosenblatt J D, et al.: Brentuximab vedotin (SGN-35) in patients with relapsed or refractory systemic anaplastic large-cell lymphoma: results of a phase II study. J Clin Oncol 30: 2190-2196, 2012

190 Pro B, Advani R H, Brice P, Bartlett N L, Rosenblatt J D, et al.: Five-Year Survival Data from a Pivotal Phase 2 Study of Brentuximab Vedotin in Patients with Relapsed or Refractory Systemic Anaplastic Large Cell Lymphoma. Blood 128: 41444144, 2016

191 Ogura M, Tobinai K, Hatake K, Ishizawa K, Uike N, et al.: Phase I / II study of brentuximab vedotin in Japanese patients with relapsed or refractory CD30-positive Hodgkin's lymphoma or systemic anaplastic large-cell lymphoma. Cancer Sci 105: 840-846, 2014

192 Bartlett N L, Chen R, Fanale M A, Brice P, Gopal A, et al.: Retreatment with brentuximab vedotin in patients with CD30positive hematologic malignancies. J Hematol Oncol 7: 24, 2014

193 Katayama R, Lovly C, Shaw A T: Therapeutic targeting of anaplastic lymphoma kinase in lung cancer: a paradigm for precision cancer medicine. Clin Cancer Res 21: 2227-2235, 2015

194 Kwak E L, Bang Y J, Camidge D R, Shaw A T, Solomon B, et al.: Anaplastic lymphoma kinase inhibition in non-small-cell lung cancer. N Engl J Med 363: 1693-1703, 2010

195 Galkin A V, Melnick J S, Kim S, Hood T L, Li N, et al.: Identification of NVP-TAE684, a potent, selective, and efficacious inhibitor of NPM-ALK. Proceedings of the National Academy of Sciences of the United States of America 104: 270275, 2007

196 Wan W, Albom M S, Lu L, Quail M R, Becknell N C, et al.: Anaplastic lymphoma kinase activity is essential for the proliferation and survival of anaplastic large-cell lymphoma cells. Blood 107: 1617-1623, 2006

197 Piva R, Chiarle R, Manazza A D, Taulli R, Simmons W, et al.: Ablation of oncogenic ALK is a viable therapeutic approach for anaplastic large-cell lymphomas. Blood 107: 689-697, 2006

198 Christensen J G, Zou H Y, Arango M E, Li Q, Lee J H, et al.: Cytoreductive antitumor activity of PF-2341066, a novel inhibitor of anaplastic lymphoma kinase and c-Met, in experimental models of anaplastic large-cell lymphoma. Mol Cancer Ther 6: 3314-3322, 2007

199 Gambacorti-Passerini C, Messa C, Pogliani E M: Crizotinib in anaplastic large-cell lymphoma. N Engl J Med 364: 775-776, 2011

200 Ordemann R, Stohlmacher J, Beuthien-Baumann B, Platzek I, van den Hoff $\mathrm{J}$, et al.: Use of targeted therapy for refractory ALK-positive anaplastic large cell lymphoma as a bridging strategy prior to allogeneic transplantation. Ann Hematol 92: 125-127, 2013

201 Gambacorti Passerini C, Farina F, Stasia A, Redaelli S, Ceccon M, et al.: Crizotinib in advanced, chemoresistant anaplastic lymphoma kinase-positive lymphoma patients. J Natl Cancer Inst 106: djt378, 2014

202 Cleary J M, Rodig S, Barr P M, Shinagare A B, Clark J W, et al.: Crizotinib as salvage and maintenance with allogeneic stem cell transplantation for refractory anaplastic large cell lymphoma. J Natl Compr Canc Netw 12: 323-326; quiz 326, 2014

203 Conyers R, Rao A, Solomon B, Seymour J F: Editor in Chief: Response to Eyre et al. "ALK-positive anaplastic large cell lymphoma: current and future perspectives in adult and paediatric 
disease". Eur J Haematol 94: 86-87, 2015

204 Kothari S, Ud-Din N, Lisi M, Coyle T: Crizotinib in anaplastic lymphoma kinase-positive anaplastic large cell lymphoma in the setting of renal insufficiency: a case report. J Med Case Rep 10: 176,2016

205 Lawrence K, Berry B, Handshoe J, Hout D, Mazzola R, et al.: Detection of a TRAF1-ALK fusion in an anaplastic large cell lymphoma patient with chemotherapy and ALK inhibitor-resistant disease. BMC Res Notes 8: 308, 2015

206 Mahuad C V, Reparaz Mde L, Zerga M E, Aizpurua M F, Casali C, et al.: Three Years Sustained Complete Remission Achieved in a Primary Refractory ALK-Positive Anaplastic T Large Cell Lymphoma Treated with Crizotinib. Rare Tumors 8: 6266, 2016

207 Mosse Y P, Lim M S, Voss S D, Wilner K, Ruffner K, et al.: Safety and activity of crizotinib for paediatric patients with refractory solid tumours or anaplastic large-cell lymphoma: a Children's Oncology Group phase 1 consortium study. Lancet Oncol 14: 472-480, 2013

208 Gambacorti-Passerini C, Horibe K, Braiteh F, Huang H -q, Shi Y, et al.: Safety and Clinical Activity Of Crizotinib In Patients With ALK-Rearranged Hematologic Malignancies. Blood 122: 4342, 2013

209 Gambacorti-Passerini C, Mussolin L, Brugieres L: Abrupt Relapse of ALK-Positive Lymphoma after Discontinuation of Crizotinib. N Engl J Med 374: 95-96, 2016

210 Marsilje T H, Pei W, Chen B, Lu W, Uno T, et al.: Synthesis, structure-activity relationships, and in vivo efficacy of the novel potent and selective anaplastic lymphoma kinase (ALK) inhibitor 5-chloro-N2-(2-isopropoxy-5-methyl-4-(piperidin-4-yl) phenyl)-N4-(2-(isopropylsulf onyl)phenyl)pyrimidine-2,4-diamine (LDK378) currently in phase 1 and phase 2 clinical trials. J Med Chem 56: 5675-5690, 2013
211 Shaw A T, Kim D W, Mehra R, Tan D S, Felip E, et al.: Ceritinib in ALK-rearranged non-small-cell lung cancer. N Engl J Med 370: 1189-1197, 2014

212 Richly H, Kim T M, Schuler M, Kim D W, Harrison S J, et al.: Ceritinib in patients with advanced anaplastic lymphoma kinase-rearranged anaplastic large-cell lymphoma. Blood 126 : 1257-1258, 2015

213 Minard-Colin V, Brugieres L, Reiter A, Cairo M S, Gross T G, et al:: Non-Hodgkin Lymphoma in Children and Adolescents: Progress Through Effective Collaboration, Current Knowledge, and Challenges Ahead. J Clin Oncol 33: 2963-2974, 2015

214 Kodama T, Tsukaguchi T, Yoshida M, Kondoh O, Sakamoto H: Selective ALK inhibitor alectinib with potent antitumor activity in models of crizotinib resistance. Cancer Lett 351: 215-221, 2014

215 Seto T, Kiura K, Nishio M, Nakagawa K, Maemondo M, et al.: CH5424802 (RO5424802) for patients with ALK-rearranged advanced non-small-cell lung cancer (AF-001JP study): a single-arm, open-label, phase 1-2 study. The Lancet Oncology 14: 590-598, 2013

216 Takeuchi K, Togashi Y, Kamihara Y, Fukuyama T, Yoshioka H, et al.: Prospective and clinical validation of ALK immunohistochemistry: results from the phase I/II study of alectinib for ALK-positive lung cancer (AF-001JP study). Ann Oncol 27: 185-192, 2016 